\title{
Advantages of a city-scale emission inventory for urban air quality research and policy: the case of Nanjing, a typical industrial city in the Yangtze River Delta, China
}

\author{
Y. Zhao ${ }^{1,2,{ }^{*} \text {, L. P. Qiu }{ }^{1, *} \text {, R. Y. Xu }{ }^{1} \text {, F. J. Xie }{ }^{3} \text {, Q. Zhang }{ }^{4} \text {, Y. Y. Yu }{ }^{5} \text {, C. P. Nielsen }}{ }^{6}$, H. X. Qin ${ }^{3}$, H. K. Wang ${ }^{1}$, \\ X. C. Wu ${ }^{1}$, W. Q. $\mathbf{L i}^{3}$, and J. Zhang ${ }^{2,7}$ \\ ${ }^{1}$ State Key Laboratory of Pollution Control \& Resource Reuse and School of the Environment, Nanjing University, \\ 163 Xianlin Ave., Nanjing, Jiangsu 210023, China \\ ${ }^{2}$ Jiangsu Collaborative Innovation Center of Atmospheric Environment and Equipment Technology (CICAEET), \\ Nanjing University of Information Science \& Technology, Jiangsu 210044, China \\ ${ }^{3}$ Nanjing Academy of Environmental Protection Science, 175 Huju Rd., Nanjing, Jiangsu 210013, China \\ ${ }^{4}$ Ministry of Education Key Laboratory for Earth System Modeling, Center for Earth System Science, Tsinghua University, \\ Beijing 100084, China \\ ${ }^{5}$ Nanjing Environmental Monitoring Central Station, 175 Huju Rd., Nanjing, Jiangsu 210013, China \\ ${ }^{6}$ Harvard China Project, School of Engineering and Applied Sciences, Harvard University, 29 Oxford St, Cambridge, \\ MA 02138, USA \\ ${ }^{7}$ Jiangsu Provincial Academy of Environmental Science, 176 North Jiangdong Rd., Nanjing, Jiangsu 210036, China \\ *These authors contributed equally to this work.
}

Correspondence to: Y. Zhao (yuzhao@nju.edu.cn)

Received: 8 June 2015 - Published in Atmos. Chem. Phys. Discuss.: 9 July 2015

Revised: 27 October 2015 - Accepted: 3 November 2015 - Published: 12 November 2015

\begin{abstract}
With most eastern Chinese cities facing major air quality challenges, there is a strong need for city-scale emission inventories for use in both chemical transport modeling and the development of pollution control policies. In this paper, a high-resolution emission inventory (with a horizontal resolution of $3 \times 3 \mathrm{~km}$ ) of air pollutants and $\mathrm{CO}_{2}$ for Nanjing, a typical large city in the Yangtze River Delta, is developed, incorporating the best available information on local sources. Emission factors and activity data at the unit or facility level are collected and compiled using a thorough on-site survey of major sources. Over 900 individual plants, which account for $97 \%$ of the city's total coal consumption, are identified as point sources, and all of the emission-related parameters including combustion technology, fuel quality, and removal efficiency of air pollution control devices (APCD) are analyzed. New data-collection approaches including continuous emission monitoring systems and real-time monitoring of traffic flows are employed to improve spatiotemporal distribution of emissions. Despite fast growth of energy con-
\end{abstract}

sumption between 2010 and 2012, relatively small interannual changes in emissions are found for most air pollutants during this period, attributed mainly to benefits of growing APCD deployment and the comparatively strong and improving regulatory oversight of the large point sources that dominate the levels and spatial distributions of Nanjing emissions overall. The improvement of this city-level emission inventory is indicated by comparisons with observations and other inventories at larger spatial scale. Relatively good spatial correlations are found for $\mathrm{SO}_{2}, \mathrm{NO}_{x}$, and $\mathrm{CO}$ between the city-scale emission estimates and concentrations at nine state-operated monitoring sites $(R=0.58,0.46$, and 0.61 , respectively). The emission ratios of specific pollutants including $\mathrm{BC}$ to $\mathrm{CO}, \mathrm{OC}$ to $\mathrm{EC}$, and $\mathrm{CO}_{2}$ to $\mathrm{CO}$ compare well to top-down constraints from ground observations. The interannual variability and spatial distribution of $\mathrm{NO}_{x}$ emissions are consistent with $\mathrm{NO}_{2}$ vertical column density measured by the Ozone Monitoring Instrument (OMI). In particular, the Nanjing city-scale emission inventory correlates better with satel- 
lite observations than the downscaled Multi-resolution Emission Inventory for China (MEIC) does when emissions from power plants are excluded. This indicates improvement in emission estimation for sectors other than power generation, notably industry and transportation. A high-resolution emission inventory may also provide a basis to consider the quality of instrumental observations. To further improve emission estimation and evaluation, more measurements of both emission factors and ambient levels of given pollutants are suggested; the uncertainties of emission inventories at city scale should also be fully quantified and compared with those at national scale.

\section{Introduction}

Emission inventories are crucial for atmospheric science research, particularly chemical transport modeling (CTM), and for air quality policymaking that seeks to identify and control pollution sources. Given China's important role in the origins and transport of air pollutants in east Asia and beyond, a number of emission inventories at national scale have been established in recent years. These include the Transport and Chemical Evolution over the Pacific mission (TRACEP, Streets et al., 2003), the Intercontinental Chemical Transport Experiment-Phase B (INTEX-B, Zhang et al., 2009), the Regional Emission inventory in ASia (REAS, Ohara et al., 2007; Kurokawa et al., 2013), and the Multi-resolution Emission Inventory for China (MEIC, http://www.meicmodel. org/). Based on "bottom-up" principles and frameworks similar to those described in Streets et al. (2003), more detailed source categories and expanded domestic information on emission factors and activity levels have been integrated into most recent work, yielding improved interannual trends in national estimates of anthropogenic air pollutant emissions (e.g., MEIC; Zhao et al., 2012a, b, 2013). Aside from the national-level work, regional emission inventories have also been established with improved understanding of local conditions for key areas with high densities of population, industry, and energy consumption, e.g., the Jing-Jin-Ji region including Beijing and Tianjin (JJJ; S. Wang et al., 2010), the Yangtze River Delta (YRD; Fu et al., 2013; Huang et al., 2011), and the Pearl River Delta (PRD; Zheng et al., 2009).

There is still need for improvement of bottom-up emission inventories however, particularly at smaller spatial scales. First, data for activity levels and emission factors used in current Chinese inventories come mostly from coarse statistics or surveys at the provincial level, except for select sectors (e.g., power generation, Zhao et al., 2008). Underlying information that is crucial to emission levels (e.g., combustion or manufacturing technologies, fuel qualities, and penetrations and removal efficiencies of various emission control devices) has often been overlooked or assumed to be uniform, inevitably reducing the accuracy and reliability of emission estimates. Without sufficient source-specific infor- mation, in particular, it is hard to identify and characterize "super-emitting" sources, which can strongly affect aggregate emission estimates. Second, the spatial and temporal distributions of emissions are often not well characterized. Emissions from most sectors are spatially allocated according to proxies, e.g., population or economic densities. However, the distribution of large sources in China is changing quickly because much industrial production is being relocated outside of urban cores, and the correlations between emissions and the usual proxies like population density are getting weaker, particularly in developed cities (Zhang et al., 2012a; Zhao et al., 2013). This introduces error into the spatial allocations. The time distribution of emissions is commonly based on expert judgment, with little reliance on realtime data sources, e.g., continuous emission monitoring systems (CEMS). Finally, some sources that may play important roles in local emissions are often missed in regional emission inventories, e.g., fugitive dust from construction and road transportation, and volatile organic compounds (VOCs) from gas stations, mainly due to data limits on such sources. Such limitations weaken capacities to research atmospheric chemistry using inventories as inputs to CTMs, and also undermine the efficacy of pollution control decision-making.

Several studies have illustrated the benefits of city-scale emission inventories that integrate more detailed local information. Timmermans et al. (2013), for example, concluded that the results of $\mathrm{NO}_{2}$ and $\mathrm{PM}_{10}$ simulations were more consistent with observations for Paris when a local emission inventory was used. In the US, model simulations of $\mathrm{NO}_{2}$ columns based on actual hourly $\mathrm{NO}_{x}$ emissions from CEMS agreed better with satellite observations than those based on default emission inputs from the US Environmental Protection Agency (US EPA; Kim et al., 2009). In China, vehicle emission inventories resolved at county level, rather than provincial level, were shown to better support air quality simulations for small regions (Zheng et al., 2014).

China is experiencing frequent severe haze episodes (Zhang et al., 2012b; Wang et al., 2013; Wang et al., 2014; R. J. Huang et al., 2014). Cities are being required to expand efforts to control air pollution, and use of CTMs for air quality assessment and policy making is becoming more routine. Due in part to weak emission inputs, however, atmospheric simulations for cities are often disappointingly inaccurate (Zifa Wang, personal communication, Institute of Atmospheric Physics, Chinese Academy of Science, 2014). Without integrating more detailed local information, some cities simply downscale a national emission inventory into high-resolution emission inputs for a CTM or develop local inventories based on the same source data and methods used for national ones. Despite improvements from some information (e.g., the precise location of large point sources), the quality and reliability of those inventories have not been well evaluated using, for example, integrated observational data as top-down constraints. Thus the emission estimates introduce large uncertainties into the city-scale air quality simulations. 
It should be noted that such improvements in emission inventories for a few megacities, including Beijing and Shanghai, have been driven by air quality planning for major events like the 2008 Summer Olympic Games and 2010 World Expo. During recent years, however, satellite observations have detected that the most significant growth in air pollution (indicated for example by vertical column densities of tropospheric $\mathrm{NO}_{2}$ ) across the country is occurring not within such megacities but in the less-developed regions around them, due to faster growth in the economies and emission sources in those areas (Zhang et al., 2012a). This finding highlights the importance of developing and assessing air pollutant emission inventories for regions other than China's much-studied megacities.

We select Nanjing, a typical large city in the YRD, to establish and evaluate a high-resolution emission inventory at city scale. As shown in Fig. S1a in the Supplement, Nanjing is the capital city of the province of Jiangsu and the second largest city in central east China following Shanghai, with a total area of $6587 \mathrm{~km}^{2}$ and population of $8 \mathrm{mil}-$ lion in 2012 (NJNBS, 2013). Intensively industrial, Nanjing consumes much more coal than many other Chinese cities with economies of similar size (e.g., Hangzhou, Qingdao, and Shenyang), and in 2012 suffered the highest number of days of haze (226) of all of China's provincial capital cities (data provided by the Nanjing Meteorological Bureau). The share of coal use in primary energy reached $89 \%$ in 2012 (Environmental Statistics, an internal database of the Nanjing Environmental Protection Bureau, NJEPB; NJNBS, 2013), much higher than the national level of $71 \%$ (NBSC, 2013). Large coal consumption and industrial and chemical production have resulted in high emissions of anthropogenic atmospheric pollutants. As the host city of the 2nd Asian Youth Games (AYG) in August 2013, Nanjing undertook various measures to control emissions in industry but allowed construction activities at thousands of sites, leading to large changes in the levels and the temporal and spatial distributions of emissions. Such changes are captured by a comprehensive city-scale emission inventory.

\section{Data and methods}

\subsection{The basic methodology}

The annual emissions in Nanjing from 2010 to 2012 are estimated with a bottom-up approach for 10 atmospheric pollutants $\left(\mathrm{SO}_{2}, \mathrm{NO}_{x}\right.$, total suspended particulates (TSP), $\mathrm{PM}_{10}$, $\mathrm{PM}_{2.5}$, black carbon (BC) or elemental carbon (EC), organic carbon (OC), $\mathrm{CO}, \mathrm{VOCs}$, and $\mathrm{NH}_{3}$ ) and the greenhouse gas $\mathrm{CO}_{2}$. At the largest scale, sources fall into six main categories: coal-fired power plants (CPP), industry (IND), transportation (TRA, including on-road and non-road subcategories), the residential and commercial sector (RES, including fossil fuel, biofuel, and biomass open burning subcate- gories, along with gas stations for the estimation of VOCs only), agriculture (AGR, including livestock farming and fertilizer use for $\mathrm{NH}_{3}$ estimation only), and fugitive dust (FUD, including that from construction sites and roads). IND is further divided into cement plants (CEM), iron and steel plants (ISP), refineries and chemical plants (RCP), solvent use (SOL; although some solvent is not used in industry, we include it in this category for classification simplicity) and other industry plants (OIN).

To improve the accuracy and reliability of the city-level emission inventory, new data are collected from various sources and modified methods are applied compared to previous studies, as briefly summarized below.

With sufficient information related to emission estimation now available, more sources can be characterized as point sources in the current inventory. These include power plants (total number in 2012, similarly for subsequent categories: $18)$, cement plants (23), iron and steel plants (2), chemical plants (173), non-ferrous metal smelters (14), lime plants (9), brick plants (31), factories representing a portion of other industrial sectors (434), and gas-fueling stations (269). The locations of point sources by category are shown in Fig. S1b and $c$ in the Supplement. The annual emissions of point sources are calculated with Eq. (1):

$E_{i}=\sum_{j, m} A_{i, j, m} \times \mathrm{EF}_{i, j, m} \times\left(1-\eta_{i, j, m}\right)$,

where $i, j$, and $m$ represent the species, individual plant, and fuel/technology type, respectively; $A$ is the activity level data; $\mathrm{EF}$ is the uncontrolled emission factor; and $\eta$ is removal efficiency of air pollutant control device (APCD).

For all the point sources, information from the Environmental Statistics database and Pollution Source Census (internal data of NJEPB) is collected and compiled to obtain the activity levels (energy consumption or industrial production) and parameters related to emission factors, plant by plant. Moreover, we conduct on-site surveys individually for all of the CPP, CEM, ISP, and RCP sources (labeled "key sources" in this paper), to get further information that is crucial for emission estimation but not covered by the official census or statistics (see details in Sect. 2.2). In 2012, all of the point sources and all of the key sources in Nanjing accounted for 97 and $96 \%$ of the city's total coal consumption, respectively, reflecting the highly centralized energy use of Nanjing. The annual activity levels for the key sources for 2010-2012 are summarized in Table S1 in the Supplement.

Besides annual levels, monthly energy consumption, industrial production, and flue-gas concentrations from CEMS are obtained whenever possible through our plant-by-plant on-site investigations. The monthly distribution of emissions from key sources is then revised based on these data.

Emissions from on-road transportation are calculated using COPERT 4 (version 9.0) (EEA, 2012). The parameters required by the model, including vehicle population by type, fleet composition by control stage (China I-IV, equivalent to 
Euro I-IV), and annual average kilometers traveled (VKT), are taken from investigations by NJEPB. The detailed information for 2012 is summarized in Tables S2 and S3 in the Supplement. The traffic flows in the city are compiled from the observations of the Intelligent Traffic Violation Monitoring System (internal data of NJEPB). In the system, cameras are used to continuously record the real-time traffic flows for most arterial roads and highways, and some residential roads in the city. The system does not cover all the roads (particularly for residential roads), and the traffic flows in those roads were simulated from the real-time monitoring data for similar roads that are covered by the system. Combining the information of traffic flows and the road net, the spatial and diurnal distributions of emissions from CORPERT can be derived. It should be noted, however, that uncertainty exists in the allocation of vehicle emissions, particularly for areas with fewer cameras installed.

For area sources including other small industry, solvent use, residential combustion, agricultural activity, and nonroad transportation, emissions are estimated following previous work (Zhao et al., 2012a, b, 2013), with up-to-date emission factors from domestic measurements and city-scale activity levels. The energy consumption data are taken from the Environmental Statistics (internal data of NJEPB) and the agricultural and industrial outputs are mainly from the Nanjing Statistical Yearbook (NJNBS, 2013). Fire counts and intensity observed from MODIS (Moderate Resolution Imaging Spectroradiometer, https://earthdata.nasa.gov/data/ near-real-time-data/firms) are used to determine the spatial and temporal distribution of emissions from biomass open burning. Regarding fugitive dust, information about individual construction sites in the city is obtained from NJEPB to improve the estimation of emission levels and spatial and temporal distributions. This includes location, period of operations, construction area, and amount of earthworks). The largest 221 construction sites in Nanjing in 2012 (accounting for $45 \%$ of the total construction area) are shown in Fig. S1c in the Supplement. The annual activity levels for the main area sources for 2010-2012 are summarized in Table S1.

\subsection{Emission factors}

As mentioned previously, parameters related to emission factors for key sources (CPP, CEM, ISP, and RCP) are obtained through on-site surveys for each plant. The parameters for CPP include boiler type, combustion technology, fuel quality (sulfur, ash, and volatile matter contents), types and pollutant removal efficiencies of APCDs (flue gas desulfurization (FGD), selective catalytic reduction (SCR)/selective non-catalytic reduction (SNCR), dust collection). Emission factors can then be determined or calculated based on the method described by Zhao et al. (2010). For cement production, the kiln type, PM removal efficiency of dust collectors, and fuel quality are investigated and emission factors are calculated following Lei et al. (2011) and Zhao et al. (2012a,
2013). For ISP, key parameters in four main processes (coking, sintering, pig iron production, and steelmaking) are obtained, including the $\mathrm{SO}_{2}$ removal rate of FGD for sintering, PM removal rate of dust collectors, and the gas release ratios of coke ovens, blast furnaces, and basic oxygen furnaces. Emission factors for each process are then calculated following Zhao et al. (2012a, 2013). For the chemical industry, the surveyed parameters include the types and amounts of raw materials and products, the types and volumes of tanks, and technologies applied for the control of VOCs. In particular, the emission factors for refineries are determined by industrial processes, including production, storage, loading, and unloading (Wei et al., 2008; US EPA, 2002; EEA, 2013). Interannual variations in these parameters for major sources are tracked in the survey so that changing emission factors over time (2010-2012) can be determined. Table 1 summarizes the penetrations and removal efficiencies of APCDs for CPP and typical industries in Nanjing from 2010 to 2012. For other industrial sources, emission factors are taken mainly from the database by Zhao et al. (2011, 2013), after incorporating the most recent results from domestic measurements. Table S4 in the Supplement summarizes the emission factors for main industrial processes.

For other sources for which local emission factors are currently unavailable, emission factors are determined based on existing studies in other parts of China. If no domestic studies are available, recommendations of US EPA (2002) are applied. Road dust emissions are estimated following US EPA (2002), based mainly on the average weight of vehicles, silt loading of the road surface, and traffic flow. Those parameters are taken from Fan et al. (2007) and Huang (2006), with some adjustments of road types for Nanjing. Emission factors of construction dust recommended by US EPA (2002) are used in this work, i.e., 0.026, 0.106, and $0.191\left(\mathrm{~kg} \mathrm{~m}^{-2}\right)$ month ${ }^{-1}$ for $\mathrm{PM}_{2.5}, \mathrm{PM}_{10}$, and TSP, respectively. The mass fractions of $\mathrm{BC}$ and $\mathrm{OC}$ in construction $\mathrm{PM}_{2.5}$ are assumed to be 2.4 and $3.4 \%$, respectively, from measurements by Zhao et al. (2009).

For gasoline stations, Nanjing completed installation of vapor recovery systems at all stations at the end of 2012. VOC emission factors for gas storage, loading, unloading and sales are determined at $0.03,0.87,0.10$ and $2.44 \mathrm{~g} \mathrm{~kg}^{-1}$, respectively (Wei et al., 2008; Fu et al., 2013). Solvents include paints for buildings and furniture, ink, fabric coating adhesives, and pesticides. VOC emission factors for decorative adhesives, interior wall paints, and wood paints are taken from Fu et al. (2013), while those for other solvent use come mainly from Wei et al. (2008).

Emission factors for non-road transportation are mainly from Zhang et al. (2010) and Ye et al. (2014). Emission factors for household biofuel use are estimated based on results of various domestic measurements as summarized in Zhao et al. (2013) and Cui et al. (2015), while those for biomass open burning are from $\mathrm{Li}$ et al. (2007). $\mathrm{NH}_{3}$ emissions from 
Table 1. The capacity penetrations, average removal efficiencies of APCDs, and flue gas release ratios for key sources in Nanjing.

\begin{tabular}{|c|c|c|c|c|c|}
\hline & \multicolumn{2}{|c|}{ CPP-FGD } & \multicolumn{2}{|c|}{ CPP-SCR/SNCR } & \multirow{2}{*}{$\begin{array}{l}\text { CEM-dust collector }^{\mathrm{a}} \\
\text { TSP removal efficiency }\end{array}$} \\
\hline & Penetration & $\mathrm{SO}_{2}$ removal efficiency & Penetration & $\mathrm{NO}_{x}$ removal efficiency & \\
\hline 2010 & $92.4 \%$ & $66.0 \%$ & $43.7 \%$ & $17.7 \%$ & $96.9 \%$ \\
\hline \multirow[t]{2}{*}{2012} & $98.3 \%$ & $81.2 \%$ & $67.4 \%$ & $77.0 \%$ & $99.6 \%$ \\
\hline & $\begin{array}{c}\text { ISP coke oven } \\
\text { Gas release ratio }{ }^{b}\end{array}$ & $\begin{array}{l}\text { ISP blast furnace } \\
\text { Gas release ratio }{ }^{b}\end{array}$ & $\begin{array}{l}\text { ISP sintering-FGD } \\
\mathrm{SO}_{2} \text { removal efficiency }\end{array}$ & $\begin{array}{l}\text { ISP pig iron production-fabric filter } \\
\text { TSP removal efficiency }\end{array}$ & $\begin{array}{l}\text { ISP steelmaking-dust collector }{ }^{\mathrm{c}} \\
\text { TSP removal efficiency }\end{array}$ \\
\hline 2012 & $0.5 \%$ & $1.5 \%$ & $70.0 \%$ & $98.8 \%$ & $96.7 \%$ \\
\hline
\end{tabular}

${ }^{\mathrm{a}}$ Including the fabric filter and the electrostatic precipitator. ${ }^{\mathrm{b}}$ The fraction of flue gas that is not recycled or collected for purification treatment, and is thus directly released to the atmosphere. ${ }^{\mathrm{c}}$ Including the fabric filter and the wet scrubber.

livestock farming and fertilizer use are taken from Dong et al. (2010), Yang (2008), and Yin et al. (2010).

\section{Results}

\subsection{Interannual variability and sector distribution of emissions}

The annual emissions of various air pollutants and $\mathrm{CO}_{2}$ from anthropogenic sources in Nanjing are shown in Fig. 1a for 2010-2012. In 2010, the total emissions of $\mathrm{SO}_{2}, \mathrm{NO}_{x}, \mathrm{CO}$, VOCs, $\mathrm{NH}_{3}, \mathrm{PM}_{2.5}, \mathrm{PM}_{10}, \mathrm{TSP}, \mathrm{CO}_{2}, \mathrm{BC}$, and $\mathrm{OC}$ are estimated to be $165,216,774,224,21,71,94,158,79976$, 6.2 , and 6.7 gigagrams $(\mathrm{Gg})$, respectively. Note the numbers here for PM emissions do not include fugitive dust from construction and transportation, to facilitate comparison with inventories that omit the source. Despite large growth in coal consumption from 2010 to 2012, the emissions of $\mathrm{SO}_{2}$ and $\mathrm{NO}_{x}$ in 2012 are estimated to be smaller than those in 2010, implying the effectiveness of emission control measures for the city in recent years. These measures mainly include the increased use of flue gas desulfurization (FGD) and selective catalytic reduction (SCR) systems in the power generation sector (see the detailed information in Table 1). The slight increase in $\mathrm{SO}_{2}$ emissions between 2011 and 2012 resulted mainly from the growth in coal consumption in industries other than power generation, where FGD systems have not been widely deployed. For $\mathrm{NO}_{x}$, the large increase in coal consumption from 31 million metric tons (Mt) in 2010 to 35 in 2011 dominated the growth of $\mathrm{NO}_{x}$ emissions, even with improved use of SCR in the power sector. From 2011 to 2012 , the growth in coal consumption was limited while the average removal efficiencies of SCR are significantly improved (as shown in Table 1), leading to reduced $\mathrm{NO}_{x}$ emissions for the whole city. PM emissions are estimated to be quite stable for the 3 years, with small increases in $\mathrm{PM}_{2.5}$ and $\mathrm{PM}_{10}$. Rising mass fractions of $\mathrm{PM}_{2.5}$ to TSP (from $45 \%$ to $48 \%$ ) indicate the difficulty in controlling emissions of finer primary particles compared to coarser ones. For VOCs and
$\mathrm{NH}_{3}$, which have not been well regulated in national action plans for air pollution prevention and control (Zhao et al., 2014), the interannual variabilities of emissions are small and driven mainly by relative stability in chemical and agricultural production, respectively. While $\mathrm{CO}_{2}$ continues to rise, no growth is estimated for CO from 2011 to 2012, implying improved overall combustion efficiency in the city.

Figure S2 in the Supplement shows the sector contributions to total emissions by year and species. From 2010 to 2012, power plants, iron and steel plants, and other industrial plants are the largest $\mathrm{SO}_{2}$ sources, contributing 41-42, $14-19$, and $32-23 \%$ of total emissions, respectively. $\mathrm{NO}_{x}$ emissions come mainly from power plants $(45 \%)$ and onroad transportation $(20 \%)$ throughout the time period. The shares of $\mathrm{SO}_{2}$ and $\mathrm{NO}_{x}$ emissions from the power sector are clearly smaller than its shares of coal consumption (57-64\%) or $\mathrm{CO}_{2}$ emissions (48-57\%), due largely to relatively stringent emission controls in the sector. It can be found that the sector distribution of $\mathrm{NO}_{x}$ emissions did not change much annually, even with clear enhancement of $\mathrm{NO}_{x}$ control in coal-fired power plants as shown in Table 1. The growth in coal consumption of power plants partly offsets the benefits of improved penetration and removal efficiency of SCR on $\mathrm{NO}_{x}$ control, and the $\mathrm{NO}_{x}$ emissions from the power sector did not vary much for the 3 years $(97,112$ and $94 \mathrm{Gg}$ for 2010, 2011, and 2012, respectively). Besides the power sector, in addition, emission controls were also improved for other sources, including the increased use of retrofitted low$\mathrm{NO}_{x}$ burners for industrial boilers, and the implementation of strict emission standards for vehicles. For example, the emissions from other industrial combustion (OIN) were estimated to decrease from 22 to $14 \mathrm{Gg}$ from 2010 to 2012, and the emissions from on-road vehicles did not change a lot despite vehicle population growth, leading to relatively small variation in sector distribution of emissions for the 3 years.

Fugitive dust, particularly that of road origin, is identified as the dominant anthropogenic source of PM emissions. The fugitive dust shares of TSP are estimated to range 64$70 \%$ during the research period, while smaller fractions are found for finer particles and carbonaceous aerosols. Apart 


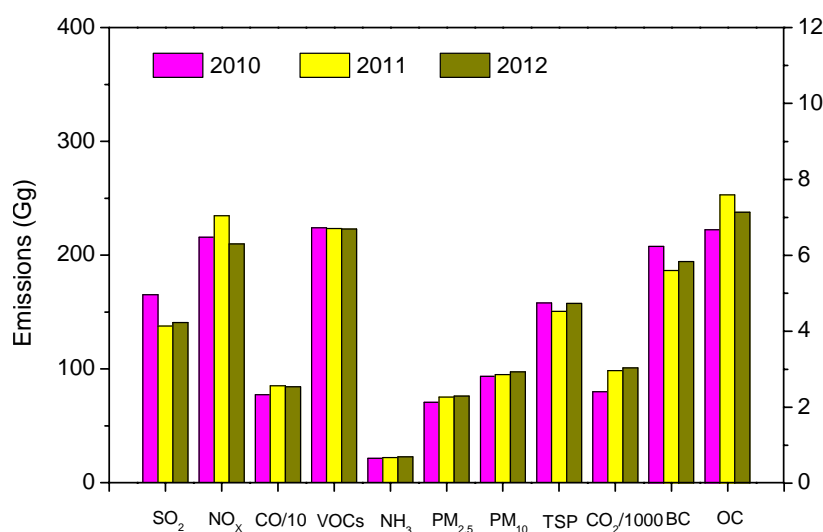

(a)

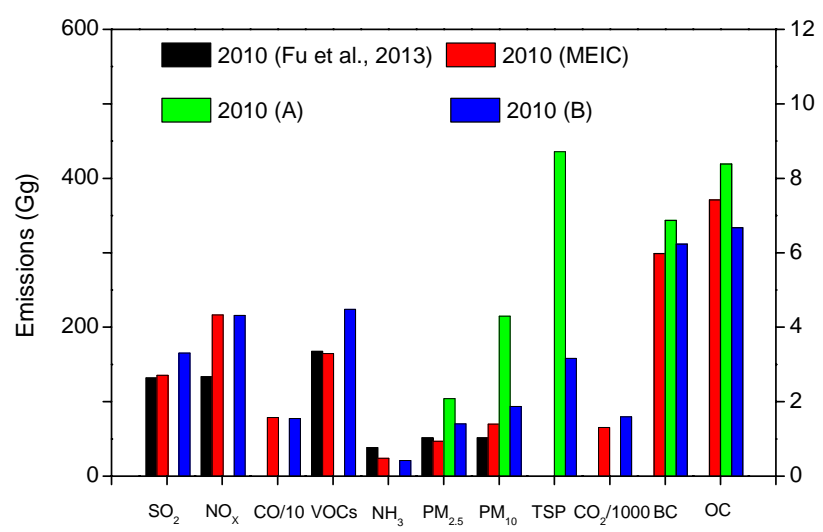

(b)

Figure 1. (a) The interannual variability of Nanjing emissions for 2010-2012 and (b) comparisons in annual emissions with other studies for 2010. The left-hand vertical axis indicates $\mathrm{SO}_{2}, \mathrm{NO}_{x}$, $\mathrm{CO}$, VOCs, $\mathrm{NH}_{3}, \mathrm{PM}_{2.5}, \mathrm{PM}_{10}$, TSP, and $\mathrm{CO}_{2}$, while the righthand axis indicates BC and OC. 2010(A) and 2010(B) refer to the emissions of current estimates with and without fugitive dust, respectively.

from fugitive dust, iron and steel production plays a significant role in PM emissions in Nanjing, with its shares of TSP, $\mathrm{PM}_{10}$, and $\mathrm{PM}_{2.5}$ calculated to be $15-16,20-23$, and 35$41 \%$, respectively. This mainly results from the large coal use by the sector, and relatively poor PM control measures of certain plants compared to other major coal-consuming sources, e.g., power plants. Iron and steel production is also identified as the biggest contributor of $\mathrm{CO}$ emissions for the city, with its share reaching $60 \%$ in 2012 , even though emission factors for the sector in Nanjing (based on field investigations) are smaller than the national average (Zhao et al., 2012a). This is partly attributed to relatively little inefficient coal combustion at other sources in the city (e.g., in small industry and residential use), resulting in much lower fractions of $\mathrm{CO}$ emissions from those sources than the na- tional averages. VOCs come mainly from chemical production $(52 \%)$ and solvent use (29-30\%). With vapor recovery systems increasingly applied, VOC emissions from gas stations decline during the research period. Despite an increase in vehicle population, the fractions of on-road transportation emissions for most species decrease from 2010 to 2012, attributed mainly to implementation of increasingly strict vehicle emission standards. From effective prohibition of burning of agricultural waste, the emission contributions of this source, mainly of particles, carbonaceous aerosols, and $\mathrm{CO}$, are also considerably reduced.

\subsection{Spatial and temporal distribution}

For simulation of atmospheric transport and chemistry, the emission inventories are allocated into a $3 \times 3 \mathrm{~km}$ grid system. For sources lacking specific location information, their emissions are assumed to be correlated with population density, with the exception of $\mathrm{NH}_{3}$, which is allocated based on the density of agricultural GDP. Shown in Fig. 2 are the spatial distributions of $\mathrm{SO}_{2}, \mathrm{NO}_{x}, \mathrm{PM}_{2.5}$ (excluding fugitive dust from construction and roads) and VOC emissions for Nanjing in 2012, and the locations of the 10 largest point sources of each species. Relatively high emission densities are found in the urban area, particularly around certain large power generation and industrial sources. As illustrated in Fig. 3, the fractions of emissions from point sources for all concerned species are estimated to exceed $50 \%$, as are those from the collective four key source types, with the exception of $\mathrm{BC}$, at $38 \%$.

Monthly distributions of $\mathrm{SO}_{2}$ emissions by sector and that of total emissions of all species for 2012 are respectively shown in Fig. S3a and b in the Supplement. Note again that fugitive dust from construction sites and roads is excluded. The results of MEIC are also provided in Fig. S3a for comparison. It can be seen that the temporal distributions of the two studies are similar except for residential emissions, which are smaller overall in this work compared to MEIC. As indicated by MODIS fire counts, over $90 \%$ of biomass open burning occurred in May-July, leading to much higher OC emissions in those 3 months compared to any other time of the year. For other species, the temporal distributions of emissions correlate closely with those of activity levels, with a drop in February attributed mainly to reduced energy supply and industrial production during the Spring Festival. Pronounced diurnal variations of on-road transportation emissions are illustrated in Fig. S4 in the Supplement, with two peaks at the rush hours. The daily shares of $\mathrm{CO}$ and VOC emissions in the morning rush hour $(16 \%)$ are slightly higher than those of $\mathrm{NO}_{x}(14 \%)$ and $\mathrm{PM}_{2.5}(15 \%)$. Based on the assumptions of COPERT, the cold start of most vehicles occurs in the morning, leading to larger $\mathrm{CO}$ and VOC emission factors during this time compared to those during stable operation of vehicles. The influence of vehicle cold starts on emissions of $\mathrm{NO}_{x}$ and $\mathrm{PM}_{2.5}$ is smaller. 


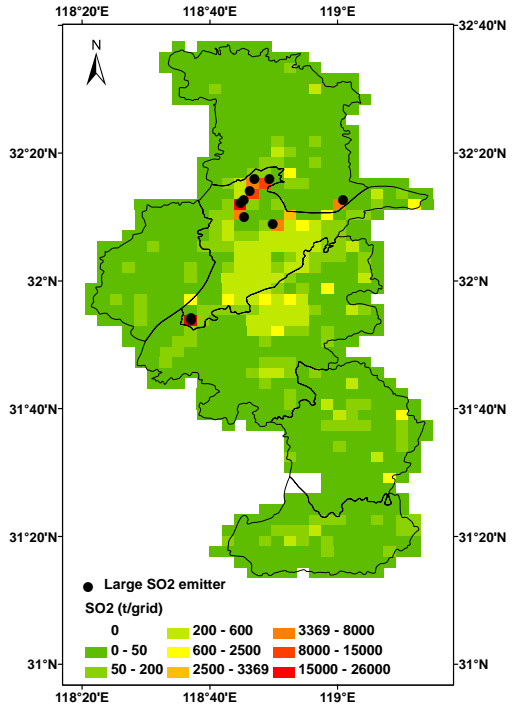

(a) $\mathrm{SO}_{2}$

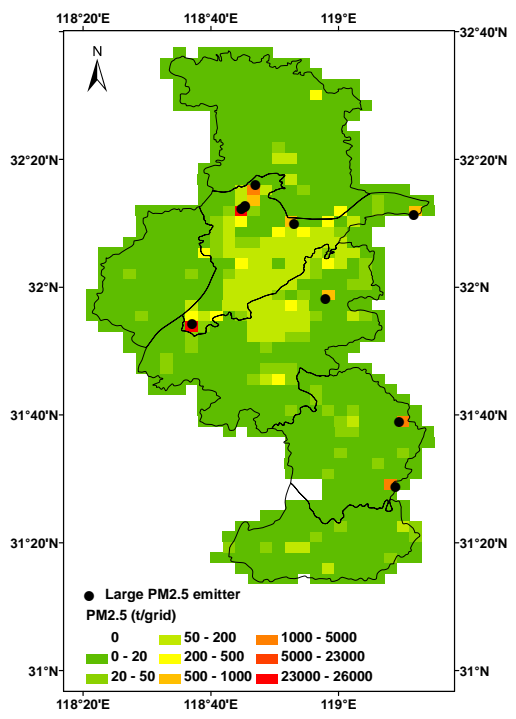

(c) $\mathrm{PM}_{2.5}$

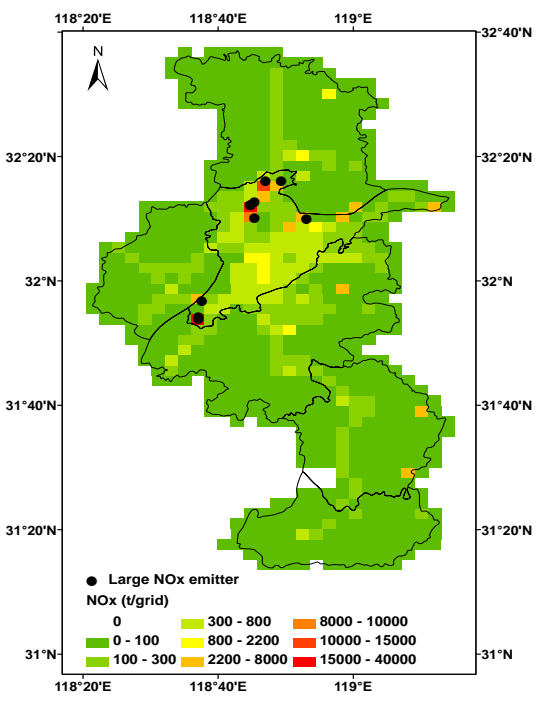

(b) $\mathrm{NO}_{\mathrm{X}}$

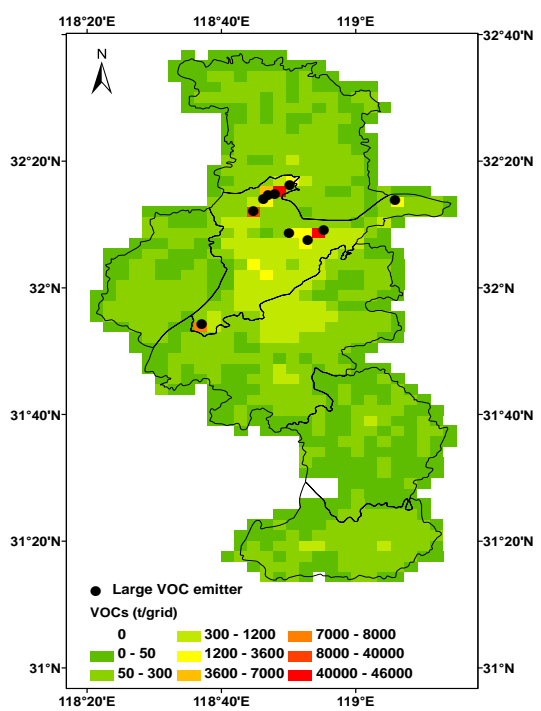

(d) VOC

Figure 2. Spatial distribution of emissions for Nanjing 2012, with locations of largest point sources indicated. (a) $\mathrm{SO}_{2} ;$ (b) $\mathrm{NO}_{x}$; (c) $\mathrm{PM}_{2.5}$ (fugitive dust from construction and road sources excluded); and (d) VOCs.

\subsection{Comparisons with other studies in emission estimates}

Figure $1 \mathrm{~b}$ compares our estimates of Nanjing emissions with those from other inventories (Fu et al., 2013; MEIC) for a common year, 2010. In the other studies, national or regional average levels for some parameters related to emissions, e.g., the penetrations and pollutant removal rates of emission control devices, are applied. These values can vary considerably from those based on plant-by-plant field investigations, leading to clear differences in emission estimates compared to the current work.
Our estimate of $\mathrm{SO}_{2}$ emissions for Nanjing is 25 and $22 \%$ higher than those of Fu et al. (2013) and MEIC, respectively, even though the plant-by-plant survey indicates an FGD penetration rate of $92 \%$ of installed power-generating capacity, higher than the provincial average of $85 \%$ used in $\mathrm{Fu}$ et al. (2013). The higher estimate results because: (1) the total coal consumption from the Environmental Statistics applied in this work is $14 \%$ larger than that provided by the Nanjing Almanac used in other studies (NJCLCC, 2011; see Sect. 4.6 for more discussion); and (2) a relatively lower removal efficiency of FGD is obtained from the on-site survey for 2010. Similar $\mathrm{NO}_{x}$ emission levels are found between the current work and MEIC, while lower emissions were provided by 


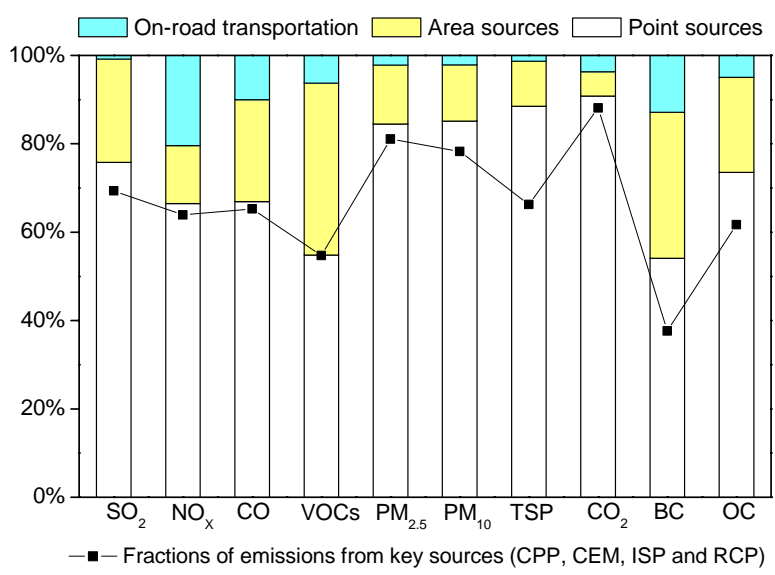

Figure 3. The emission fractions of point sources, area sources, and on-road transportation, and those of key sources of total emissions in Nanjing, 2012.

Fu et al. (2013). According to a field survey, the penetration rate of SCR/SNCR increased from 44 to $67 \%$, and the $\mathrm{NO}_{x}$ removal efficiency increased from 18 to $77 \%$ during 2010 2012 (Table 1). The penetration rate is much larger compared to the provincial average of $22 \%$ applied in MEIC and Fu et al. (2013), partly offsetting a discrepancy in estimated emissions caused by larger activity levels used in the current cityscale inventory.

Our estimates for $\mathrm{PM}_{2.5}, \mathrm{PM}_{10}$, and $\mathrm{BC}$ emissions (without fugitive dust emissions) are larger than those of $\mathrm{Fu}$ et al. (2013) or MEIC in 2010. This results mainly from larger emissions from industry (particularly iron and steel production), as the survey revealed that relatively old and inefficient wet dust collectors were still used at some plants. VOC emissions, however, are estimated to be lower than MEIC indicates, due mainly to very little coal or biomass burning in the city-level statistics.

VOC emissions estimated in this work in 2010 are $34 \%$ larger than Fu et al. (2013) and 36\% larger than MEIC. In particular, emissions from refineries and chemical plants, calculated using detailed information on each plant's inputs of raw materials and the product types and amounts, are $116 \%$ higher than those in regional inventories (Fu et al., 2013). Thus the fraction of total VOC emissions attributed to industrial processes is estimated to be $48 \%$ by us, larger than the YRD average level of $34 \%$ (Fu et al., 2013). Given Nanjing is a city with large petroleum refining and chemical industries, and that much higher production of crude oil, gasoline, diesel and liquefied petroleum gas is reported than in other YRD cities in 2010 (NJNBS, 2013), the higher VOC emissions indicated by the plant-based inventory is believed to better reflect the city's true industrial structure.

For $\mathrm{CO}$, our estimates are $12 \%$ higher for industry than those of MEIC, but 26 and $37 \%$ lower respectively for residential and transportation sectors, resulting in $2 \%$ lower emissions for anthropogenic sources as a whole. The discrepancy in sector contributions is caused mainly by the high percentage of centralized coal combustion in the city: power, iron and steel, cement, and chemical plants consumed over $95 \%$ of the city's coal, based on our field survey. Our $\mathrm{CO}_{2}$ emission estimate is $22 \%$ higher than that of MEIC, mainly resulting from the difference in coal consumption reported by the Environmental Statistics database and the city almanac.

\section{Assessment of the city-scale emission inventory}

The current inventory is assessed to gauge improvements of emission estimates using a city-scale framework. The interannual variability, spatial distributions, and correlations of a number of species of the inventory are evaluated by comparison to available satellite and ground observations, and to downscaled national emission inventories.

\subsection{Evaluation of interannual trends and spatial distribution of $\mathrm{NO}_{x}$ emissions with satellite observations}

The interannual trend in $\mathrm{NO}_{x}$ emissions estimated bottomup is compared with that of $\mathrm{NO}_{2}$ vertical column densities (VCDs) based on satellite observations. The VCDs of tropospheric $\mathrm{NO}_{2}$ are retrieved from the Ozone Monitoring Instrument (OMI) by the Royal Netherlands Meteorological Institute (Boersma et al., 2007, 2011), using monthly data with a spatial resolution of $0.125^{\circ} \times 0.125^{\circ}$ (data source: http://www.temis.nl/airpollution/no2col/ no2regioomimonth_v2.php). Illustrated in Fig. 4 are annual emissions estimated in this work for Nanjing from 2010 to 2012 and VCDs from 2005 to 2012 for four regions: Nanjing, Shanghai, four provinces in the YRD (including Jiangsu, Zhejiang, Anhui, and Shanghai), and a rectangular region containing Nanjing (see Fig. S1a for reference). The first two represent $\mathrm{NO}_{2}$ at city levels, while the latter two represent regional levels. To eliminate seasonal variations, $\mathrm{NO}_{2}$ VCDs are presented as 12-month moving averages, calculated as the means of the data for the previous and subsequent 6 months. All the data are normalized to the 2010 level of Nanjing. While $\mathrm{NO}_{2}$ VCDs started declining around 2008 for Shanghai, it kept increasing for the rest of the YRD region including Nanjing until 2012. Clearly higher than the regional levels, the average $\mathrm{NO}_{2} \mathrm{VCD}$ for Nanjing approached that of Shanghai after 2010. This implies, on the one hand, the benefits of Shanghai's strict emission controls of on-road vehicles and big power plants (K. Huang et al., 2014), implemented in advance of other regions. On the other hand, the growth of $\mathrm{NO}_{2}$ for the rest of the YRD demonstrates the spread of air pollution source regions from major metropolitan areas to less developed cities nearby, and suggests the need for increased efforts in emission and pollution abatement in those areas, as indicated by Zhang 


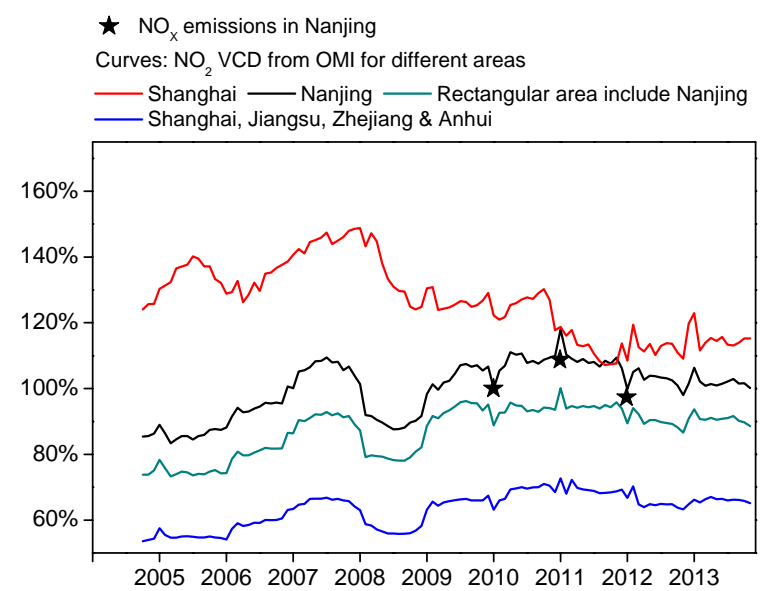

Figure 4. The interannual trends in $\mathrm{NO}_{2}$ vertical column density (VCD) from OMI for selected regions (see Fig. S1a for reference) and the bottom-up $\mathrm{NO}_{x}$ emissions for 2010-2012. All the data are normalized to 2010 level in Nanjing.

et al. (2012a). Decreased emissions in Nanjing are clearly indicated by this work after 2011, attributed mainly to the national policy of compulsory installation and running of SCR devices in the power sector. This interannual variation shows good consistency with that of $\mathrm{OMI} \mathrm{NO} \mathrm{NCD}_{2}$.

It should be noted that uncertainties exist in the comparison between the interannual variations in emissions and VCDs and the results should be interpreted cautiously. First, the biases of $\mathrm{NO}_{2} \mathrm{VCD}$ retrieval from OMI were reported to reach $40 \%$ attributed probably to the errors in the air mass factor calculations (Boersma et al., 2007, 2011). Such uncertainties are potentially larger than the interannual changes in $\mathrm{NO}_{x}$ emissions of Nanjing between 2010 and 2012, and thus weaken the comparison. However, since the bottom-up emissions are not evaluated by the absolute values but the relative trends of VCDs, the effects of $\mathrm{NO}_{2} \mathrm{VCD}$ retrieval uncertainties on the comparison could partly be mitigated. Another uncertainty comes from meteorology. As shown in Fig. S5 in the Supplement, the interannual changes in meteorological parameters were small, except for precipitation during 2010 2012 in Nanjing. The varied precipitation could change the data sampling of retrieval, and thereby influence the $\mathrm{NO}_{2}$ VCD levels. Finally, the period for emission and VCD comparison is relatively short. Even the $\mathrm{NO}_{2}$ VCDs kept decreasing slightly after 2012, the benefits of $\mathrm{NO}_{x}$ emission control could not be fully confirmed as the emission inventory for the most recent years are still unavailable due to the delay of activity data report. Analysis of the long-term trends in emissions from the bottom-up method is further suggested for better understanding the $\mathrm{NO}_{x}$ pollution in the area.

To further assess possible improvement of emission estimates by the current city-level inventory, the spatial distribution of monthly means of $\mathrm{OMI} \mathrm{NO}_{2} \mathrm{VCD}$ in summer (JuneAugust) 2010 over Nanjing is compared with that of two emission studies: (1) city-level emissions at a spatial resolution of $3 \times 3 \mathrm{~km}$ given in the current work, and (2) MEIC emissions developed at the provincial level with a resolution of $5 \times 5 \mathrm{~km}$. For the purpose of visualization and further analysis, the emissions are reallocated to a $0.125^{\circ} \times 0.125^{\circ}$ grid system from the original spatial distributions, consistent with the resolution of retrieved $\mathrm{OMI} \mathrm{NO} \mathrm{NCD}_{2} \mathrm{VC}$. We assume that the $\mathrm{NO}_{2} \mathrm{VCD}$ levels from satellite observations reflect the anthropogenic $\mathrm{NO}_{x}$ emissions of the city for the following reasons. $\mathrm{NO}_{x}$ emissions in east China are predominantly anthropogenic (Mijling et al., 2013); lightning and soil sources as a share of total emissions are estimated to peak in July, when they account for $9 \%$ and $12 \%$, respectively (Lin, 2012). $\mathrm{NO}_{x}$ emissions in Nanjing are clearly larger than in surrounding areas (Huang et al., 2011), and the $\mathrm{NO}_{2} \mathrm{VCD}$ level over the city is believed to be most influenced by local emissions.

As shown in Fig. 5, a similar spatial pattern of $\mathrm{NO}_{x}$ is captured by the gridded emissions and satellite observations, and relatively higher pollution in the urban area in the center of the city is indicated, attributed mainly to the combined effects of intensive transportation and large point sources. The emission inventories, however, underestimate the highpollution areas compared to OMI observations, particularly MEIC. To further gauge improvement in spatial distribution by the city-scale emissions, correlations between the gridded emissions and the VCD are analyzed. As shown in Fig. 6a, the correlation coefficients $(R)$ between the emissions and the VCDs are calculated to be 0.450 and 0.408 for this work and MEIC, respectively, indicating better agreement by the city-scale inventory. Moreover, a sensitivity test on the correlation coefficients is conducted through step-wise exclusion of the grid cells with the largest emissions. Along with the increase in excluded grid cells, the $R$ for this city-scale emission inventory remains above 0.43 , while those of MEIC sharply decrease (Fig. 6b). In order to estimate emissions of the whole country, the MEIC is based mainly on energy and economic statistics at the provincial level, though it includes a limited number of major point sources, e.g., power plants with relatively good documentation and large emissions. Emissions from other point sources are based on coarser inputs due to constraints of time, labor, and data availability. The current study, in contrast, compiled detailed information for all power plants and most other industrial sources in Nanjing through comprehensive survey investigation, as described in Sect. 2. Better estimates of emission levels and spatial distributions should thus be expected, particularly for small- or medium-sized emission sources. Once the grid cells dominated by major power plants are excluded from the two inventories, as shown in Fig. 6c, the current city-scale emissions still correlate well with satellite observations $(R=0.436)$, while MEIC shows little correlation $(R=0.085)$. The results reflect that inventories compiled at the provincial or regional level better estimate emissions of large sources than small- or medium-sized ones, due to rel- 


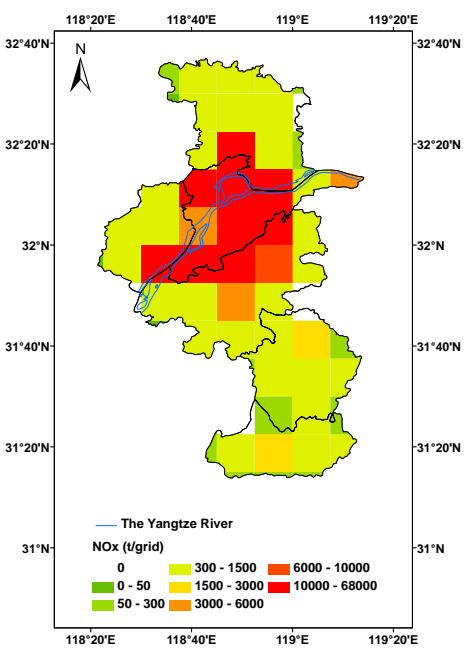

(a) Emissions: This study

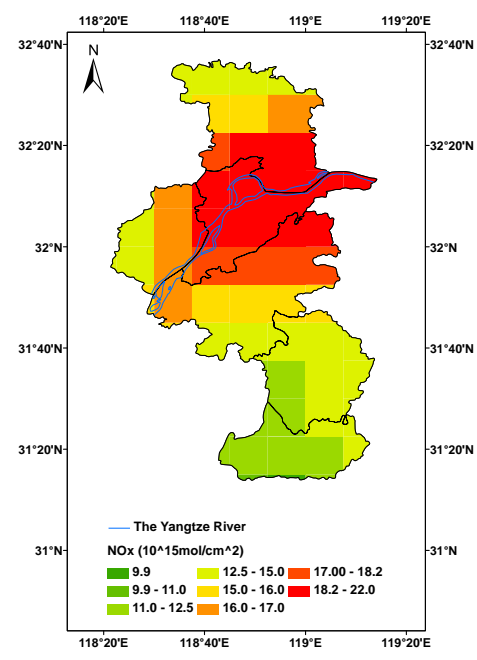

(b) VCD from OMI

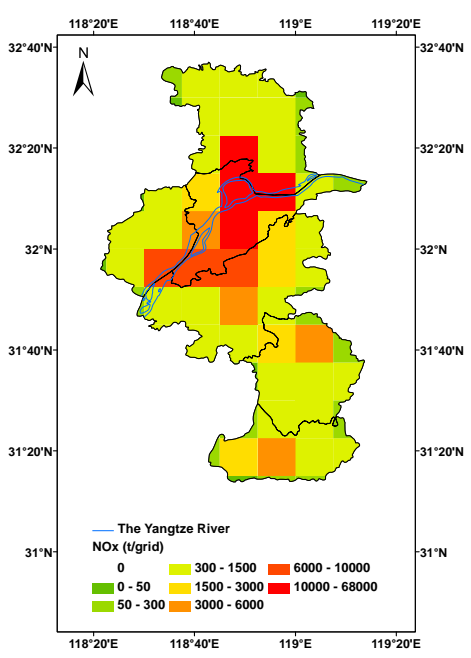

(c) Emissions: MEIC

Figure 5. (a) Spatial distribution of city-scale $\mathrm{NO}_{x}$ emissions in this study, (b) summer $\mathrm{NO}_{2}$ vertical column density (VCD) from $\mathrm{OMI}$, and (c) $\mathrm{NO}_{x}$ emissions from MEIC for Nanjing, 2010. The resolution is $0.125^{\circ} \times 0.125^{\circ}$.

ative availability of information on power plants but much poorer nationwide data availability for other industrial plants. When focusing on smaller regions like cities, however, detailed information on more emission sources from on-site surveys becomes crucial for improving emission estimates.

It should be noted that high $\mathrm{NO}_{2}$ VCDs are found over the Yangtze River by OMI (roughly following the dark red zone in Fig. S6 in the Supplement), while current emission inventories cannot capture this. Possible underestimation of emissions from ships is indicated. Due to data limits, only ships arriving or leaving the port of Nanjing are taken into account in the current city-scale inventory, while those passing through Nanjing are omitted. Further investigation of the vessel flow along the Yangtze River is thus necessary to improve the estimation of ship emissions, which may be particularly influential at small spatial scales. Besides the ships, the emissions from factories along the river could also contribute to the high VCDs.

\subsection{Spatial correlations between pollutant emissions and ambient concentrations from ground observations}

Ambient concentrations for selected pollutants from ground observations are used to test the city-scale emission inventory. Daily averages of $\mathrm{SO}_{2}, \mathrm{NO}_{2}, \mathrm{CO}$, and $\mathrm{PM}_{2.5}$ concentrations for 2012 are obtained from the nine state-operated monitoring stations in urban/suburban Nanjing, mapped in Fig. S1d. The $\mathrm{SO}_{2}, \mathrm{NO}_{2}, \mathrm{CO}$, and $\mathrm{PM}_{2.5}$ concentrations were measured by Ecotech EC9850B, Ecotech EC9841B, Ecotech EC9830B, and Met One 1020 analyzers, respectively. The emissions of specific pollutants around each site with a grid cell size of $0.04^{\circ} \times 0.04^{\circ}$ are calculated from the $3 \times 3 \mathrm{~km}$ gridded inventories, and correlations with annual mean concentrations of corresponding species are analyzed. Since none of the city's key sources (CPP, CEM, ISP, or RCP) are located in those grid cells, the effects of individual big sources on the correlation between emissions and observation are assumed to be limited.

As shown in Fig. 7a, modest agreement is found in spatial patterns between the observed concentrations and the emissions for $\mathrm{SO}_{2}$ and $\mathrm{NO}_{x}\left(\mathrm{NO}_{2}\right)$, with the $R$ calculated to be 0.58 and 0.46 , respectively. $\mathrm{SO}_{2}$ and $\mathrm{NO}_{x}$ have average atmospheric lifetimes of several days and 1 day, respectively, thus the ambient concentrations are expected to partly reflect emission intensities nearby, and the correlation analysis adds support for the reliability of the city-scale emission inventory. The $y$ intercepts in Fig. 7a can be considered as the approximations of regional background levels of $\mathrm{SO}_{2}$ and $\mathrm{NO}_{2}$, and the value for $\mathrm{NO}_{2}$ is relatively high compared to $\mathrm{SO}_{2}$. Since the YRD is a developed region with a large economy, high energy consumption, and, particularly large vehicle population and intensive transportation, the background levels of $\mathrm{NO}_{2}$ could be enhanced, and the local emissions in Nanjing city thus have a less significant impact on $\mathrm{NO}_{2}$ concentrations. Moreover, in urban areas with plenty of emission sources and relatively large emission density, $\mathrm{NO}$ was found to account for a large fraction of $\mathrm{NO}_{x}$ in the ambient atmosphere (Zhou et al., 2008). As the dominating component of primary $\mathrm{NO}_{x}$ directly from emission sources, $\mathrm{NO}$ is more difficult to be oxidized to $\mathrm{NO}_{2}$ in urban than in rural or remote regions, attributed to less resident time for chemistry conversion in urban regions. Given the nine state-operated monitoring sites are all located in urban/suburban Nanjing, the observed $\mathrm{NO}_{2}$ concentrations were less sensitive or correlated to the $\mathrm{NO}_{x}$ emissions, compared to the case of $\mathrm{SO}_{2}$, and 

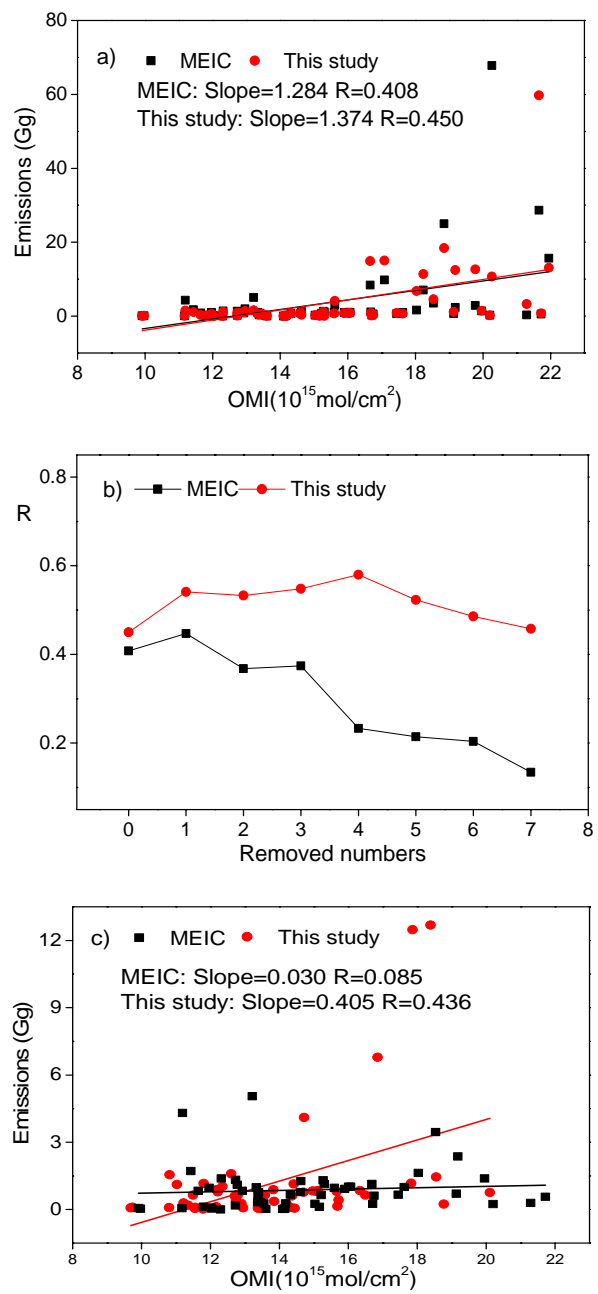

Figure 6. Spatial correlation between $\mathrm{NO}_{x}$ emissions from city- and national-scale inventories and $\mathrm{NO}_{2}$ vertical column density (VCD) from OMI, in Nanjing, 2010 for (a) all grids, (b) step-wise exclusion of grid cells with largest emissions, and (c) grid cells without power plant emissions.

it leads to the smaller slope of ambient $\mathrm{NO}_{2}$ levels to $\mathrm{NO}_{x}$ emissions and the lower correlation coefficient in Fig. 7a.

As shown in Fig. 7b, the correlation coefficient for $\mathrm{CO}$ is calculated to be 0.61 , and it reaches 0.86 when the observation of the Caochangmen site is excluded, where extremely high emissions are calculated but low ambient levels were observed (to be further discussed in Sect. 4.4). Even with a longer lifetime (weeks to months) than $\mathrm{SO}_{2}$ or $\mathrm{NO}_{x}, \mathrm{CO}$ in the atmosphere over Nanjing results mainly from primary emissions from incomplete combustion, implying reasonable agreement between emissions and concentrations. However, emissions from small coal combustion sources still cannot be fully tracked or precisely quantified, and this evidence is thus tentative.
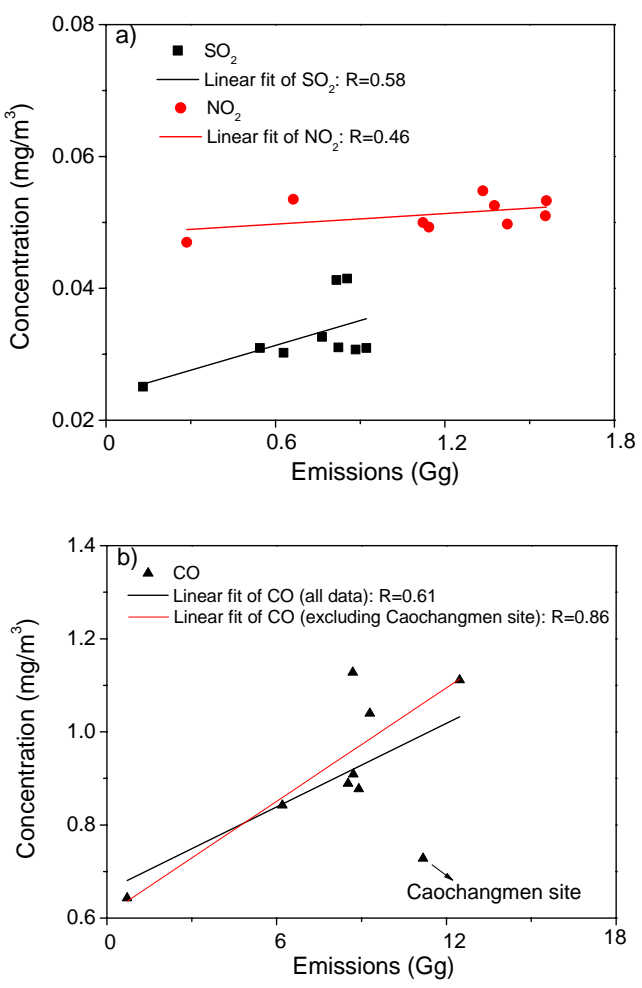

Figure 7. Linear regression of emissions and concentrations at the nine state-operated stations in Nanjing, 2012. (a) $\mathrm{SO}_{2}$ and $\mathrm{NO}_{x} / \mathrm{NO}_{2}$; (b) CO.

\subsection{Evaluation of emissions against top-down constraints from observations}

For certain pairs of pollutants that come from common sources and thus share emission characteristics, or weakly reactive species that are relatively stable in the atmosphere, correlations of ambient concentrations can provide useful "top-down" constraints on "bottom-up" estimates of primary emissions. In this work, the correlations of three pairs of species in the atmosphere - $\mathrm{BC}$ and $\mathrm{CO}, \mathrm{OC}$ and $\mathrm{EC}$, and $\mathrm{CO}_{2}$ and $\mathrm{CO}$ - are analyzed based on daily mean concentrations from ground observations in 2012. Combining the mass or molar ratios of emissions for corresponding species allows further evaluation of the city-scale inventory.

\subsection{1 $\quad \mathrm{BC}$ and $\mathrm{CO}$}

$\mathrm{BC}$ and $\mathrm{CO}$ both result from incomplete combustion of solid fuels and certain industrial processes such as coking. With a relatively long atmospheric lifetime, $\mathrm{CO}$ is usually recognized as a tracer of pollution transport. Combined with $\mathrm{BC}$ levels, it can also be used to test emission inventories of the two species (most at regional or national scale), which is particularly useful for BC given its relatively large emission uncertainties (Kondo et al., 2011; Wang et al., 2011; Zhao et al., 2011, 2012a). We follow the method presented 
in Wang et al. (2011) but focus on evaluating the city-level, top-down emission ratio of $\mathrm{BC}$ to $\mathrm{CO}$ based on observations at Caochangmen in Nanjing (point A in Fig. S1d in the Supplement). We choose this site for emission evaluation for two main reasons. First, it is an urban site and thus assumed to be more representative of the city emissions, compared to suburban/rural sites that are more influenced by emissions from broader areas. Second, Caochangmen is the biggest and the most comprehensive state-operated station in the city. Among all the nine state-operated sites in Nanjing, it is the one and only station that conducts observations not only for the six criterion pollutants (i.e., $\mathrm{SO}_{2}, \mathrm{NO}_{2}, \mathrm{CO}$, $\mathrm{O}_{3}, \mathrm{PM}_{10}$, and $\mathrm{PM}_{2.5}$ ), but also for certain species including $\mathrm{BC}$ used here and $\mathrm{CO}_{2}$ used later. Daily means of $\mathrm{BC}$ and $\mathrm{CO}$ concentrations are calculated based on the hourly data from continuous observations using Magee AE 31 and Ecotech EC9830B analyzers, respectively, and the correlation between the two species are then evaluated and used to check the bottom-up emission inventories. Since ambient levels of BC and CO do not only depend on emissions but also on atmospheric processes (e.g., wet and dry depositions of $\mathrm{BC}$, chemical reactions of $\mathrm{CO}$ with $\mathrm{OH}$, and mixing of both $\mathrm{BC}$ and $\mathrm{CO}$ ) that exert different influences on the two species (Wang et al., 2011), the top-down emission ratio of $\mathrm{BC}$ to $\mathrm{CO}\left(\mathrm{BC} /\left.\mathrm{CO}\right|_{\mathrm{E} \text {,top-down }}\right)$ is calculated from the observed $\mathrm{BC} / \mathrm{CO}\left(\mathrm{dBC} /\left.\mathrm{dCO}\right|_{t}\right)$ by excluding the influence of the above-mentioned atmospheric processes, as indicated in Eq. (2):

$\mathrm{dBC} /\left.\mathrm{dCO}\right|_{t}=\mathrm{BC} /\left.\mathrm{CO}\right|_{\text {E,top-down }} F_{\text {dry }} F_{\text {chem }} F_{\text {mixing }} F_{\text {wet }}$.

$F_{\text {wet }}$ indicates the wet deposition screening. Based on precipitation data from the Weather Underground website (http: //www.wunderground.com/history/), the data in precipitation days were excluded to eliminate the effects of wet deposition. $F_{\text {dry }}, F_{\text {chem }}$, and $F_{\text {mixing }}$ indicate the screening of dry deposition of $\mathrm{BC}$, chemical reactions of $\mathrm{CO}$ with $\mathrm{OH}$, and mixing of both $\mathrm{BC}$ and $\mathrm{CO}$, respectively. Following the methods by Wang et al. (2011), $F_{\text {mixing }}$ is set at 1 and $F_{\text {chem+dry }}$ is calculated to be 0.88 , based on the lifetime of $\mathrm{BC}$ and $\mathrm{CO}$ in the atmosphere.

As shown in Fig. 8, the annual ratio of $\mathrm{BC}$ to $\mathrm{CO}$ from observations is estimated to be $0.0071 \mu \mathrm{g} \mathrm{m}^{-3} \mathrm{ppbv}^{-1}$ by linear regression with the reduced major axis method (Hirsch and Gilroy, 1984), and it is $0.0073 \mu \mathrm{g} \mathrm{m}^{-3} \mathrm{ppbv}^{-1}$ if the days of wet deposition are excluded. Once influence from other atmospheric processes is further eliminated, $\mathrm{BC} / \mathrm{CO}_{\mathrm{E} \text {,top-down }}$ rises to 0.0084 , lower than the ratio from the city-scale bottom-up emission inventory at 0.0097 , or that from the MEIC national inventory at 0.0095 . It should be noted that the downtown observation site is influenced heavily by local transportation, particularly gasoline vehicles that have relatively high $\mathrm{CO}$ but low $\mathrm{BC}$ emissions. Therefore, the topdown ratio of $\mathrm{BC}$ to $\mathrm{CO}$ observed at the site is expected to be somewhat lower than that of emissions over the entire city. The comparison of top-down and bottom-up results is thus

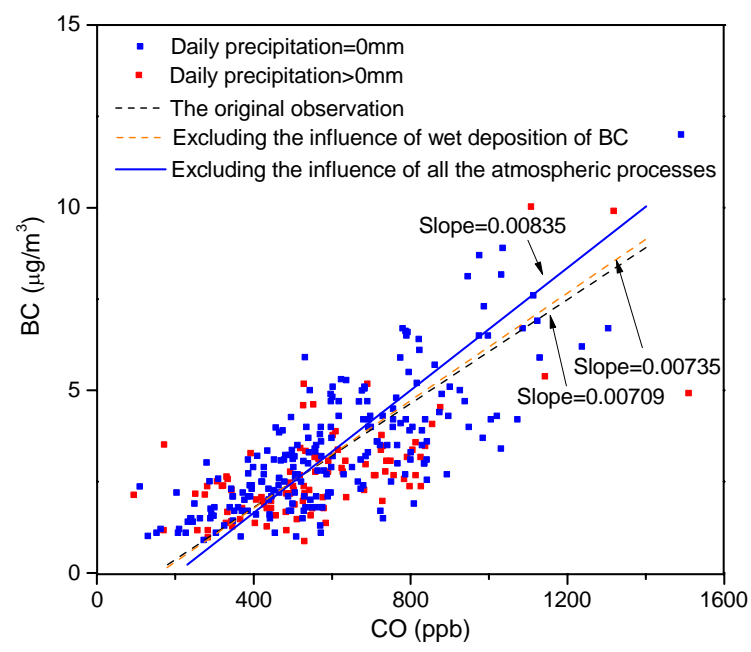

Figure 8. The correlation of daily $\mathrm{BC}$ and $\mathrm{CO}$ concentrations at Caochangmen site and the emission ratios of $\mathrm{BC}$ to $\mathrm{CO}$ from bottom-up inventories for Nanjing, 2012.

roughly consistent with the city-scale emission inventory, although possible overestimation of $\mathrm{BC}$, or underestimation of $\mathrm{CO}$ emissions is indicated.

Aside from mean annual levels, comparisons are also conducted for seasonal $\mathrm{BC}$ to $\mathrm{CO}$ ratios, as summarized in Table 2. The highest $\mathrm{BC} /\left.\mathrm{CO}\right|_{\mathrm{E}, \text { top-down }}$ is found in summer, while the lowest is in winter. Such seasonal variation, however, is not indicated in the current bottom-up emission inventory, for the following possible reasons. First, as described in Sect. 2, the temporal distribution of emissions is based on the investigation of large and medium enterprises. However, the species of concern here, especially BC, come largely from small industrial and residential sources, for which temporal information is still lacking. For transportation, the increased cold start of vehicles in winter also leads to higher $\mathrm{CO}$ emissions that cannot be fully captured by COPERT (Cai and Xie, 2010; Xiao et al., 2004) and could then lead to an overestimate of $\mathrm{BC} / \mathrm{CO}$ from the bottom-up method. Second, although Caochangmen is located in urban Nanjing, it is inevitably influenced by emissions from wider regions outside the city that are not quantified in the cityscale inventory. For example, biomass burning, which has a higher $\mathrm{BC}$ to $\mathrm{CO}$ ratio than exists in the ambient atmosphere, occurs more frequently in less-developed areas such as northern Jiangsu and Anhui provinces than in Nanjing. According to MODIS, 79\% of agricultural fire points in Jiangsu 2012 were found in summer, elevating the ambient $\mathrm{BC} / \mathrm{CO}$ in that season. Third, uncertainty exists about the estimation of $F_{\text {chem. }}$. In winter, the lowest $\mathrm{OH}$ densities in the boundary layer resulting from the weakest radiation lead to the smallest CO sink, and the opposite is true in summer (Seiler et al., 1984; Huang et al., 2013). The elevated $F_{\text {chem }}$ in summer should thus lead to reduced $\mathrm{BC} /\left.\mathrm{CO}\right|_{\mathrm{E}, \text { top-down. }}$ In this work, however, the seasonal difference in $F_{\text {chem }}$ cannot be 
Table 2. The average concentrations of $\mathrm{BC}$ and $\mathrm{CO}$ and correlation of $\mathrm{BC}$ to $\mathrm{CO}$ from observations at Caochangmen and the ratios of bottom-up BC to CO emissions by season in Nanjing, 2012.

\begin{tabular}{|c|c|c|c|c|c|c|c|c|}
\hline & \multicolumn{7}{|c|}{ Urban observation } & \multirow{2}{*}{$\begin{array}{r}\text { Bottom-up inventory } \\
\mathrm{BC} /\left.\mathrm{CO}\right|_{\text {E,bottom-up }} \\
\left(\mu \mathrm{g} \mathrm{m}^{-3} \mathrm{ppbv}^{-1}\right)\end{array}$} \\
\hline & $\begin{array}{l}\text { Avg. BC } \\
\left(\mu \mathrm{g} \mathrm{m}^{-3}\right)\end{array}$ & $\begin{array}{r}\text { Avg. } \mathrm{CO}^{\mathrm{a}} \\
(\mathrm{ppbv})\end{array}$ & $\begin{array}{l}\text { Avg. BC } \\
\left(\mu \mathrm{g} \mathrm{m}^{-3}\right)\end{array}$ & $\begin{array}{r}\text { Avg. } \mathrm{CO}^{\mathrm{b}} \\
(\mathrm{ppbv})\end{array}$ & $\begin{array}{r}\mathrm{BC} / \mathrm{CO}^{\mathrm{a}} \\
\left(\mu \mathrm{g} \mathrm{m}^{-3} \mathrm{ppbv}^{-1}\right)\end{array}$ & $\begin{array}{r}\mathrm{BC} / \mathrm{CO}^{\mathrm{b}} \\
\left(\mu \mathrm{g} \mathrm{m}^{-3} \mathrm{ppbv}^{-1}\right)\end{array}$ & $\begin{array}{r}\mathrm{BC} /\left.\mathrm{CO}\right|_{\text {E,top-down }}{ }^{\mathrm{c}} \\
\quad\left(\mu \mathrm{g} \mathrm{m}^{-3} \mathrm{ppbv}^{-1}\right)\end{array}$ & \\
\hline Spring & 2.946 & 661.3 & 3.009 & 684.9 & 0.0070 & 0.0072 & 0.0082 & 0.0101 \\
\hline Summer & 2.644 & 490.3 & 3.000 & 491.0 & 0.0083 & 0.0085 & 0.0097 & 0.0096 \\
\hline Autumn & 4.206 & 619.6 & 3.822 & 627.1 & 0.0081 & 0.0081 & 0.0092 & 0.0095 \\
\hline Winter & 3.007 & 615.0 & 3.068 & 637.7 & 0.0051 & 0.0060 & 0.0068 & 0.0096 \\
\hline Overall & 3.156 & 588.0 & 3.264 & 600.5 & 0.0071 & 0.0074 & 0.0084 & 0.0097 \\
\hline
\end{tabular}

${ }^{a}$ All the observation data included. ${ }^{b}$ The influence of wet deposition excluded. ${ }^{c}$ The influence of wet and dry deposition, chemical reactions with $\mathrm{OH}$ radicals, and mixing excluded.

precisely quantified precisely based on existing studies, and the same $F_{\text {chem }}$ has to be used for all seasons, leading to possible overestimation of $\mathrm{BC} /\left.\mathrm{CO}\right|_{\mathrm{E}, \text { top-down }}$ for summer and underestimation for winter.

\subsubsection{OC and EC}

EC and primary OC result from incomplete combustion, and the ratio of $\mathrm{OC}$ to EC concentrations is used to evaluate carbonaceous aerosol emissions and the formation of secondary organic aerosols (SOA) through the EC tracer method (Castro et al., 1999). From 2011 to 2013, ambient EC and OC in downwind Nanjing were collected using quartz filters and analyzed with a DRI Model 2001 thermal/optical carbon analyzer by season ( $\mathrm{Li}$ et al., 2015). The ratios of primary OC to $\mathrm{EC},(\mathrm{OC} / \mathrm{EC})_{\text {pri }}$, were then determined based on the observation. Attributed to limited sampling size, Li et al. (2015) chose the lowest daily OC/EC during the sampling period for each season as the seasonal $(\mathrm{OC} / \mathrm{CE})_{\text {pri }}$, to exclude the effects of SOA (see Fig. S7 for the observed time series of ambient $\mathrm{OC}$ to $\mathrm{EC}$ ratio). The (OC / EC) pri values were then estimated to be $1.70,1.27,1.53$, and 1.85 for spring, summer, autumn, and winter, respectively, with an annual average of 1.59. In this work, we adopt those results and assume that they serve as a top-down constraint of carbonaceous aerosol emissions. From the bottom-up estimates, the emission ratios of OC to BC in our city-scale emission inventory and MEIC are respectively 1.38 (for 2012) and 1.24 (for 2010, the most recent year for which MEIC emissions are available), both of which are lower than the top-down (OC / EC) pri from observations. With few emission sources nearby, the observation site is thought to be less influenced by local sources (e.g., on-road transportation that has a relatively low emission OC to $\mathrm{BC}$ ratio) compared to the regional transport of pollutants (Li et al., 2015). Thus some sources with high OC to BC ratios that are uncommon in Nanjing but more dispersed outside the city contribute significantly to the observed concentrations at the site. Those sources include residential fossil and biomass combustion and biomass open burning. The OC to $\mathrm{BC}$ emission ratios of Jiangsu and Anhui provinces surrounding Nanjing are estimated respectively at 1.91 and 2.13 (Zhao et al., 2013), clearly larger than the local emission ra- tio of Nanjing. Moreover, the carbonaceous aerosol sampling procedure used by Li et al. (2015) would lead to positive artifacts of OC measurement and elevated OC to EC, since usage of quartz filters adsorbs some semivolatile organic compounds (SVOC) in the ambient atmosphere (Cheng et al., 2009). The system bias of OC quantification from this sampling approach was estimated to reach $50 \%$ in US (Chow et al., 2010; McDonald et al., 2015), and it was found to be $100 \%$ in Beijing, China (Hu et al., 2008). However, the bias can vary largely between cities, and it has not been well quantified for Nanjing, making the evaluation of emission inventories of carbonaceous aerosols less conclusive. Finally, uncertainty also exists in the (OC / EC) $)_{\text {pri }}$ determination by $\mathrm{Li}$ et al. (2015), as the sample size from off-line measurements was small. To evaluate the city-level OC and BC emissions better, therefore, more observational research with improved (e.g., long-term and continuous) measurements is strongly recommended at sites where local sources dominate, and the artifacts of the measurement should be sufficiently analyzed.

\subsection{3 $\mathrm{CO}_{2}$ and $\mathrm{CO}$}

$\mathrm{CO}_{2}$ is a well-known greenhouse gas, with the main anthropogenic sources fossil energy combustion and industrial processes. The ratios of $\mathrm{CO}_{2}$ to $\mathrm{CO}$ emissions differ between source types, reflecting varying combustion efficiencies. The observed ratio of $\mathrm{CO}_{2}$ to $\mathrm{CO}$ levels in the atmosphere can thus be used as an indicator of energy efficiency, as well as a top-down test of emissions estimated bottom-up. The annual molar ratios of $\mathrm{CO}_{2}$ to $\mathrm{CO}$ emissions in Nanjing are calculated to be 65.7, 73.6, and 76.1 for 2010, 2011, and 2012, respectively, significantly higher than those in Beijing in 2008 (32.8, Zhao et al., 2012a). They are also higher than the mixing ratios observed in rural Beijing in 2008 (26.8, Y. Wang et al., 2010) or at Hatetuma Island (HAT), a remote site located off the coast of continental east Asia and influenced by air masses transported from east Asian countries from late fall to early spring (34.5, Tohjima et al., 2014). Given the large discrepancy, data from measurements in urban Nanjing (Caochangmen, Point A in Fig. S1d) are further analyzed to test the emissions. Daily mean concentrations of $\mathrm{CO}_{2}$ and $\mathrm{CO}$ are derived from hourly observations using 
Thermo 410i and Ecotech EC9830B analyzers, respectively, for all of 2012. To exclude the effects of biogenic emissions that prevail in warm seasons, data for the winter months (January, February, and December) are used. The prevailing wind directions over Nanjing in winter are east and northeast, and large point sources, accounting for $64 \%$ of the city's $\mathrm{CO}_{2}$ emissions, are located to the east and northeast of Caochangmen, supporting use of the observational data for the current purpose.

The average observed concentrations of $\mathrm{CO}_{2}$ and $\mathrm{CO}$ in winter were $421 \mathrm{ppmv}$ and $608 \mathrm{ppbv}$, respectively. Based on the cumulative probability distribution of daily $\mathrm{CO}$ concentrations (as shown in Fig. S8 in the Supplement), the whole data set is divided into three subsets: (1) below the 30th percentile (with average $\mathrm{CO}$ and $\mathrm{CO}_{2}$ concentrations at $350 \mathrm{ppbv}$ and $410 \mathrm{ppmv}$, respectively), (2) between the 30th and 95th percentile (677 ppbv for CO and $424 \mathrm{ppmv}$ for $\mathrm{CO}_{2}$ ), and (3) above the 95th percentile (above 1200 ppbv for $\mathrm{CO}$ and 448 ppmv for $\mathrm{CO}_{2}$ ). We consider that subset (1) represents air masses from relatively clean areas outside Nanjing, and subset (2) a well-mixed blend of sources of $\mathrm{CO}_{2}$ and $\mathrm{CO}$ over Nanjing. Subset (3) is assumed to indicate extremely serious regional pollution episodes, in which pollutants were trapped in a shallow inversion layer (Y. Wang et al., 2010). Subset (2) is believed to best reflect the typical effects of local emissions and is used for bottom-up emission comparisons.

Illustrated in Fig. 9 is the $\mathrm{CO}_{2}-\mathrm{CO}$ correlation estimated with the reduced major axis method based on surface observations and the $\mathrm{CO}_{2}$ to $\mathrm{CO}$ ratios from bottom-up emission inventories for Nanjing. Our estimate of the $\mathrm{CO}_{2}$ to $\mathrm{CO}$ ratio (76.1) is closer to observations (86.9) than MEIC (52.8), implying improvement in the current city-scale inventory. The observed $\mathrm{CO}_{2}$ to $\mathrm{CO}$ ratio, however, should theoretically be lower than that from emissions for the following three reasons. First, compared to $\mathrm{CO}$, the observation of $\mathrm{CO}_{2}$ at an urban site would be more influenced by sources within a broader region than the city, as $\mathrm{CO}_{2}$ has a longer lifetime in the atmosphere. Thus it is not fully representative of the very centralized and large $\mathrm{CO}_{2}$ emissions inside the city, particularly those from large point sources (e.g., 17 power plants and 2 iron and steel plants, which are estimated to account for $78 \%$ of total $\mathrm{CO}_{2}$ emissions in Nanjing), and the $\mathrm{CO}_{2}$ to $\mathrm{CO}$ ratio from observations should be reduced. Second, the current emission inventory only includes the primary $\mathrm{CO}$ emissions, while there may be a fair amount of secondary $\mathrm{CO}$ from the oxidation of NMVOC (non-methane VOC). Duncan et al. (2007) estimated that CO from NMVOC oxidation equaled nearly $50 \%$ of global primary CO emissions. Given the intensive refineries and chemical plants and thereby elevated NMVOC emissions in Nanjing, considerable secondary $\mathrm{CO}$ from NMVOC oxidation can be expected, leading to a lower ratio of $\mathrm{CO}_{2}$ to $\mathrm{CO}$ from observations than that from primary emissions. To partly exclude the effects of NMVOC oxidation, we recalculated the ambient $\mathrm{CO}_{2}$ to
CO ratio at 91.9 based on the hourly concentration data from 18:00 to 06:00 LT for subset (2), when the temperature was lower and photochemistry was slower. The value is larger than 86.9 based on daily average concentration data, attributed mainly to less formation of secondary CO. Third, as discussed previously, the Caochangmen site is influenced heavily by local transportation that exhibits a lower $\mathrm{CO}_{2}$ to $\mathrm{CO}$ emission ratio than industry. We believe that the higher $\mathrm{CO}_{2}$ to $\mathrm{CO}$ ratio from observations than bottom-up emissions reflect the uncertainties from both approaches. On the one hand, emissions from certain species and sectors need to be further improved, e.g., $\mathrm{CO}$ from vehicles might be underestimated by the current work, since relatively poor management of vehicle emissions in China cannot be tracked by COPERT. On the other hand, we speculate that possible bias also exists in observations, with more discussion to follow in Sect. 4.4.

The larger molar ratios of $\mathrm{CO}_{2}$ to $\mathrm{CO}$ in Nanjing than in Beijing, both from observations and emissions, are attributed mainly to the structure of emission sources. Nanjing is a city with intensive heavy industry, and over $90 \%$ of coal was consumed by power plants, iron and steel plants, cement plants, and large chemical enterprises with relatively high energy efficiencies, leading to elevated ratios of $\mathrm{CO}_{2}$ to $\mathrm{CO}$ in emissions, and thereby also in concentrations. Transportation, particularly gasoline vehicles, is additionally a significant emission source of $\mathrm{CO}$ compared to $\mathrm{CO}_{2}$, and plays important roles in molar ratios of $\mathrm{CO}_{2}$ to $\mathrm{CO}$. For instance, Y. Wang et al. (2010) found significantly increased ambient $\mathrm{CO}_{2} / \mathrm{CO}$ in September 2008 (46.4 ppmv ppmv ${ }^{-1}$ ) compared to September 2005-2007 (23-29 ppmv ppmv $^{-1}$ ) in Beijing, resulting mainly from the temporary ban of vehicles for the Beijing Olympic Games and thereby decreased $\mathrm{CO}$ emissions. In 2012 the vehicle population in Beijing was 3.5 times that of Nanjing (NJNBS, 2013). Transportation was estimated to contribute 29-37\% of anthropogenic CO emissions in Beijing from various studies (MEIC; Zhao et al., 2013), but the value is much smaller in Nanjing (10\%), elevating the molar ratio of $\mathrm{CO}_{2}$ to $\mathrm{CO}$ in the city.

\subsection{Evaluation of local ground observations based on the city-scale emission inventory}

While ground observations can be used as top-down constraints on emissions, we suggest that a high-resolution emission inventory can also be used to evaluate observational data. Although detailed local information demonstrably improves emission estimation, inconsistencies still exist between the city-scale emission inventory and ground observations of $\mathrm{CO}$ at Caochangmen. These inconsistencies include (1) the significant increase in correlation coefficients between $\mathrm{CO}$ emissions and ambient concentrations at stateoperated monitoring sites when the data at Caochangmen are excluded (from 0.61 to 0.86), as described in Sect. 4.2 and Fig. 7b; and (2) the higher $\mathrm{CO}_{2} / \mathrm{CO}$ from observations at Caochangmen than that from city-scale emissions, 
which contradicts expectations based on atmospheric chemistry principles, as described in Sect. 4.3 and shown in Fig. 9. This suggests the possibility of instrumental or other error reflected in the relatively low $\mathrm{CO}$ concentrations observed at Caochangmen in 2012. Thus we conduct a comparison of $\mathrm{CO}$ concentrations between Caochangmen and another state-operated site, Shanxilu, for 2012 and 2014. Similar to Caochangmen, Shanxilu is also an urban site, $3.5 \mathrm{~km}$ from Caochangmen. Frequency histograms of hourly CO concentrations at the two sites for 2012 and 2014 are shown in Fig. S9. It can be seen that $\mathrm{CO}$ levels at Caochangmen were significantly lower than those at Shanxilu in 2012 (Fig. S9a) but the CO levels were quite similar at the two sites in 2014 (Fig. S9b). Moreover, a clear difference $(\sim 30 \%)$ in $\mathrm{CO}$ levels between 2012 and 2014 was found at Caochangmen (Fig. S9c) but not at Shanxilu (Fig. S9d). Given the very close distance and similar characteristics of the two sites, we tentatively assume that there should not be a significant difference in $\mathrm{CO}$ levels between them. Thus we conduct a sensitivity test by increasing the $\mathrm{CO}$ concentrations at Caochangmen by $30 \%$ in 2012, and repeat the assessment of the city-scale emission inventory with the revised CO data set. The correlation coefficient between $\mathrm{CO}$ emissions and ambient concentrations at the nine state-operated sites would be increased substantially, from 0.62 to 0.83 . The ratio of $\mathrm{CO}_{2}$ to $\mathrm{CO}$ in winter from the revised observational data would decrease from to 86.9 to 66.8 , close to and lower than the ratio from the bottom-up city-scale inventory (76.1), consistent with the expectation that observed $\mathrm{CO}_{2} / \mathrm{CO}$ should be smaller than emissions. If only hourly data from 18:00 to 06:00 LT are applied to mitigate the effects of secondary $\mathrm{CO}$ formation from NMVOC oxidation, an even closer ambient $\mathrm{CO}_{2}$ to $\mathrm{CO}$ ratio to emission inventory result would be estimated to be 70.7. Such data revision is clearly speculative, but encourages further analysis when observational data for a longer period become available at both sites. The city-scale emission inventory may thus provide a basis to raise questions about the quality of local ground observations, which should not be taken for granted.

\subsection{Comparison between city and national inventories for certain sources}

To further explore the effects of methods and data employed in emission estimation at city and national levels, we conduct comparisons of emission levels and spatial distributions between the current inventory and MEIC for given pollutants from typical sources, including $\mathrm{SO}_{2}$ from power generation, $\mathrm{NO}_{x}$ from transportation, and $\mathrm{PM}_{2.5}$ from industry, for 2010 in Nanjing. Our estimates are reallocated to a resolution of $5 \times 5 \mathrm{~km}$, the same as MEIC, so that spatial correlations between the two inventories can be quantified.

As shown in Fig. 10a, relatively good correlation in the spatial distributions of $\mathrm{SO}_{2}$ emissions from power generation is found for the two inventories, with the $R$ estimated to

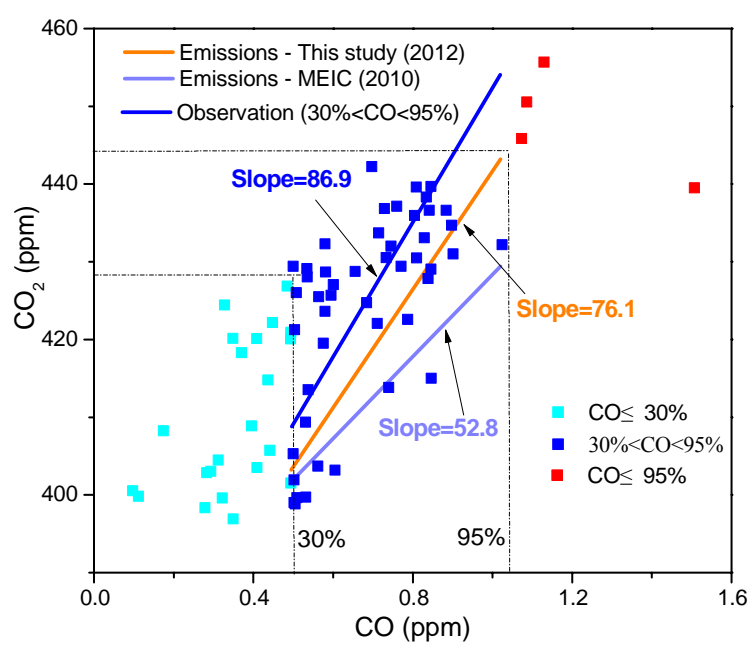

Figure 9. The correlation of daily $\mathrm{CO}_{2}$ and $\mathrm{CO}$ concentrations at Caochangmen site and the emission ratios of $\mathrm{CO}_{2}$ to $\mathrm{CO}$ from bottom-up inventories for Nanjing, 2012. The wintertime concentrations with $\mathrm{CO}$ between the 30th and 90th percentiles are used for the correlation analysis.

be 0.74 . The result indicates consistency between the emission estimates of the two studies for large point sources, as might be expected given their shared reliance on relatively transparent, publicly available information on power plants nationwide. Since detailed field investigations of individual sources are lacking, however, national inventory studies have to rely on standard information for which routine updates or revisions are not guaranteed, and the latest changes in individual plants, including the closure of small power units or relocation of some power plants, cannot be tracked fully or on a timely basis. This is reflected by a number of data points in Fig. 10a with positive emission values on one axis but zero on the other. Regarding the total emission levels, MEIC is $35 \%$ lower than our estimate, attributed mainly to the different $\mathrm{SO}_{2}$ removal efficiencies of FGD applied in the two studies. Based on the field measurement data that were reported by individual plants and verified by the local environmental protection bureau, the average removal efficiency of FGD for power plants in Nanjing in 2010 is estimated to be $66 \%$, lower than the values commonly applied by researchers in national emission assessments (e.g., above $70 \%$, Zhao et al., 2013). The discrepancy reveals the value of site-specific investigation of key parameters influencing emission estimates, including the $\mathrm{SO}_{2}$ removal rate of FGD.

For $\mathrm{NO}_{x}$ from transportation, the spatial $R$ is calculated to be 0.652 between the two estimates, and the value would rise to 0.75 if the two grid cells with the largest emissions in the city-scale inventory were excluded, as shown in Fig. 10b. Similar to the power sector, the general spatial pattern of emissions from transportation for the two inventories is largely consistent. The emissions in MEIC, however, are much more concentrated in downtown urban regions com- 

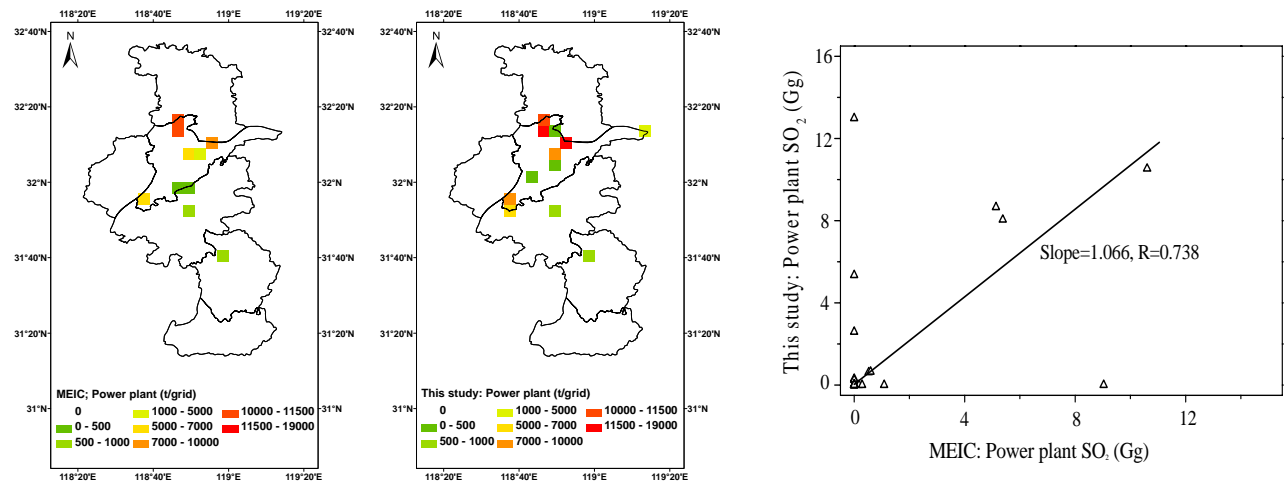

(a) Power plant: $\mathrm{SO}_{2}$
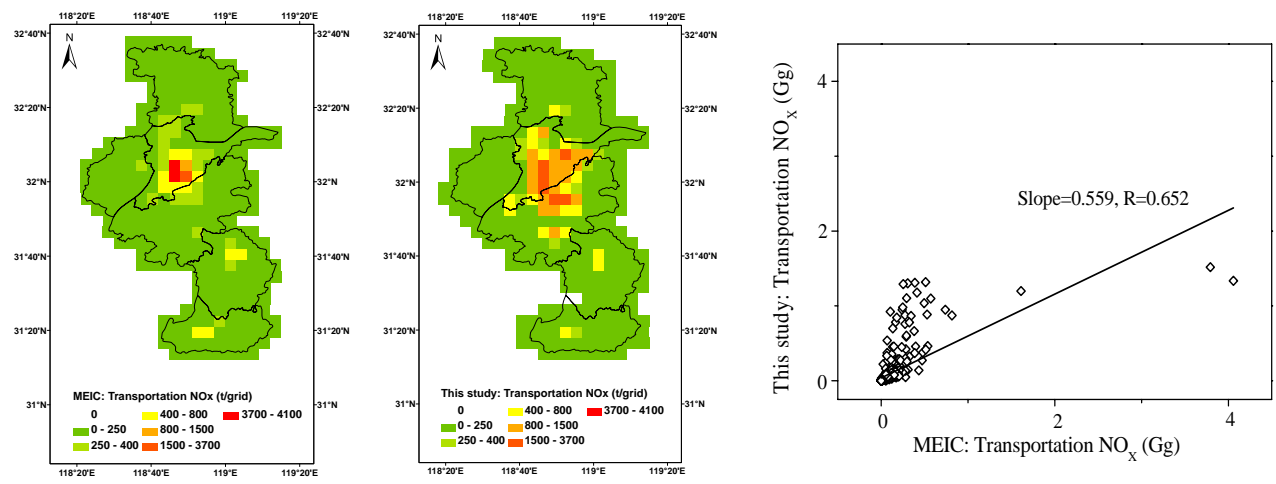

(b) Transportation: $\mathrm{NO}_{\mathrm{X}}$
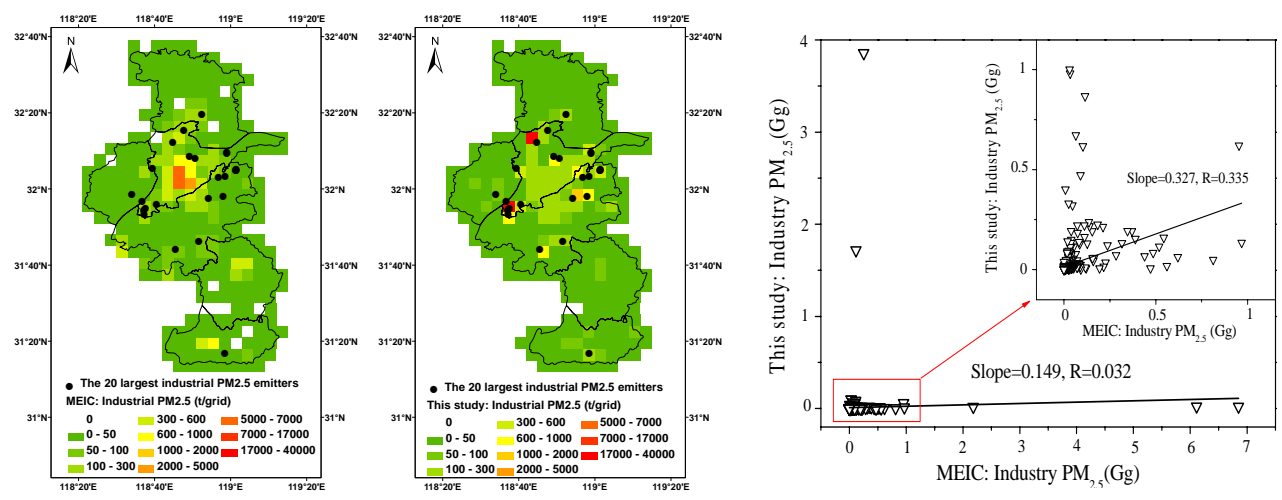

(c) Industry: $\mathrm{PM}_{2.5}$

Figure 10. Spatial distribution and linear regression of emissions from city-scale and national inventories (MEIC) for (a) $\mathrm{SO}_{2}$ from power generation, (b) $\mathrm{NO}_{x}$ from transportation, and (c) $\mathrm{PM}_{2.5}$ from industry for Nanjing, 2010.

pared to our estimate, resulting from differences in spatial densities of population versus transportation flows based on road networks. The former is commonly applied in spatial distribution of national emission inventories, while the latter, when available through field investigations or real-time recordings, are used in city-scale inventories like ours. The total $\mathrm{NO}_{x}$ emissions from transportation estimated by MEIC are $27 \%$ lower than those by the city-scale inventory, suggesting introduction of considerable uncertainty when emis- sions estimated to be the national level are downscaled to the city level based on proxies like population or economic activity.

In contrast to the above two cases, little correlation is found between the two estimates in the spatial distribution of $\mathrm{PM}_{2.5}$ emissions from industrial sources (Fig. 10c). Shown in the maps of Fig. 10c are not only the $\mathrm{PM}_{2.5}$ emissions but also the locations of the 20 largest emitting industrial enterprises. A clear discrepancy is observed between the distribu- 
tion of those sources and emissions from MEIC, while much stronger consistency is found in the current work. Without sufficient information on individual sources, inventories developed at the national level tend to allocate large fractions of emissions into urban regions with relatively high densities of population and/or economic activity, assuming good spatial correlation between emissions and those proxies. Such correlation, however, likely weakens as pollution control in urban regions is implemented because it includes significant relocation of emission sources to suburban or rural areas (a primary element of urban pollution control policy in China). The total $\mathrm{PM}_{2.5}$ emissions from industrial sources estimated by MEIC are $50 \%$ lower than our estimate, moreover, because: (1) a national emission inventory based on the sector-average levels of controls and emission factors cannot capture atypical, extremely large sources (super emitters); and (2) coal consumption from the official statistics used by MEIC is much lower than the aggregate of individual sources evaluated in the field survey (3.0 vs. 5.0 Mt for Nanjing, 2010). Comparisons and correlation analyses between inventories developed at different spatial scales, therefore, show the advantages of thorough investigation of individual emission sources, particularly for cities with many large industrial enterprises like Nanjing.

\subsection{Uncertainty assessment of the city-scale emission inventory}

The uncertainties of China's national emission inventories have been estimated using a Monte-Carlo simulation, as described in our previous studies (Zhao et al., 2011, 2013). Targeting city scale, however, the uncertainty of current inventory for Nanjing is more difficult to be systematically quantified, as many emission factors are city- or device-dependent and their probability distributions could not be fully defined without sufficient field measurement records. In general, the uncertainties of emissions from power and industry sectors are expected to be reduced compared to the national level, as the "key sources" in the city contribute significantly to the fuel consumption and production of those sectors. As described in Sect. 2, the activity levels and emission factors for those key sources were complied plant by plant or obtained through on-site surveys, leading to relatively small biases in emission estimation. For most area sources, the emission factors used in this work were hardly improved compared to previous national/regional inventories; thus large uncertainties remain in those sources. Given the tiny fractions of emissions by those sources in Nanjing, however, their contribution on the uncertainty of total city emissions is expected to be limited. Very high uncertainty is expected for fugitive dusts that are generally not included in national/regional inventories, as little local information is available to improve the emission factors. Given the large shares of fugitive dusts to primary PM emissions (Fig. S2), field measurements on construction sites and road dusts are suggested for better emission estimation in Nanjing.

We try further to identify some common sources of uncertainty in the development of city-level emission inventories, including (1) the inconsistencies of activity-level data from various sources; and (2) the downscaling of activity data or emissions due to a lack of city-level information.

There has been continuing concern about the accuracy and reliability of China's energy statistics for more than a decade (Sinton, 2001). Statistics from various sources report divergent energy consumption levels for the country, and the choice of activity-level data for emission inventories continues to be debated. For example, China's total energy use from national statistics has been inconsistent with that aggregated from provincial statistics, driving considerable differences in national emission estimates (Akimoto et al., 2006; Guan et al., 2012; Zhao et al., 2013). While Akimoto et al. (2006) concluded that an emission inventory based on province-byprovince statistics were in better agreement with satellite observations, Guan et al. (2012) indicated that over-reporting in provincial energy statistics could be a factor. At the city level, however, there are far fewer evaluations of the accuracy of energy statistics. We find a clear discrepancy in energy consumption data in statistical sources for Nanjing: the total coal consumption in 2010 was reported at $27.9 \mathrm{Mt}$ in the Nanjing Almanac (NJCLCC, 2011), while the value from the Environmental Statistics was $14 \%$ higher, $31.9 \mathrm{Mt}$. The disparity results mainly from differences in data collection for small emission sources (enterprises). While data reporting systems and resulting data quality have been gradually improved for large- and medium-scale enterprises, many smallscale ones still do not maintain well-documented records on energy consumption, and the energy use of those enterprises is poorly captured by the city almanac (personal communications with officials from Nanjing Municipal Commission of Economy and Information Technology, 2014). Aimed at pollution control, the environmental statistical system obtains and verifies energy data for each enterprise through field surveys, and we thus believe that these energy consumption data are more complete and reliable for emission inventory development. The uncertainty from such varied statistical sources could be reduced as retirement of small boilers and/or closure of small enterprises increases. Although the Nanjing Almanac stopped reporting coal consumption for the city after 2010, the Environmental Statistics indicates that the combined share of coal consumption by large- and medium-sized sources increased from $84 \%$ in 2010 to $91 \%$ in 2012, attributed to the closure of small enterprises, reporting highly uncertain energy data during the period.

Besides problems in the energy data, uncertainty in the city-scale emission inventory can also result from a lack of information on certain industrial sectors in the city statistics. If field surveys of individual sources cannot be conducted due to labor or time constraints, emissions have to be estimated by downscaling national or provincial estimates. 
Table 3. Comparisons of emission estimations using method A (plant-by-plant survey) and B (downscaling from provincial levels) for brick, lime, and copper production in Nanjing, 2012.

\begin{tabular}{|c|c|c|c|c|c|c|c|c|c|c|}
\hline & \multicolumn{2}{|c|}{ Production $^{\mathrm{a}}$} & \multicolumn{2}{|c|}{$\mathrm{SO}_{2}$ emissions } & \multicolumn{2}{|c|}{$\mathrm{NO}_{x}$ emissions } & \multicolumn{2}{|c|}{$\mathrm{PM}_{2.5}$ emissions } & \multicolumn{2}{|c|}{$\mathrm{CO}$ emissions } \\
\hline & Method A & Method B & $\mathrm{B} / \mathrm{A}$ & $(\mathrm{B}-\mathrm{A}) / \mathrm{OIN}^{2}$ & $\mathrm{~B} / \mathrm{A}$ & (B-A)/OIN & $\mathrm{B} / \mathrm{A}$ & (B-A)/OIN & $\mathrm{B} / \mathrm{A}$ & $(\mathrm{B}-\mathrm{A}) / \mathrm{OIN}$ \\
\hline Brick & 14 & 29 & & & 2.0 & $10 \%$ & 2.0 & $19 \%$ & 2.0 & $13 \%$ \\
\hline Lime & 207 & 2050 & 9.9 & $6 \%$ & 9.9 & $22 \%$ & 3.6 & $15 \%$ & 9.9 & $24 \%$ \\
\hline Copper & 1.3 & 39 & 31.1 & $24 \%$ & & & 3.6 & $13 \%$ & & \\
\hline
\end{tabular}

${ }^{\mathrm{a}}$ The units are $10^{9}$ bricks, $10^{3} t$-lime and $10^{3} t$-copper, respectively. ${ }^{\mathrm{b}}$ Recall from Sect. 2.1 that OIN indicates emissions from other industries (iron and steel, cement production, and chemical industry excluded) estimated at the city level.

To evaluate the resulting uncertainty, air pollutant emissions from non-ferrous metal smelting and the production of brick and lime in Nanjing 2012 are recalculated by the downscaling provincial estimates method (method B). In this method, emissions in the Jiangsu province are first calculated based on the provincial statistics and provincial average levels of emission control. Emissions in Nanjing are then obtained according to Nanjing's fraction of certain proxy (industrial GDP in this case) out of the whole province. The results are compared with those based on detailed source investigations (method A). Shown in Table 3 are the product output (activity level) and pollutant emissions estimated by methods A and B. The activity levels estimated from provincial-level information are much higher than the actual industrial production aggregated from individual plants, suggesting that downscaling produces emission overestimates. For example, gaseous pollutant emissions calculated with method B are 2, 10, and 30 times larger than those produced by method A for brick, lime, and copper production, respectively. For PM emissions, the discrepancies in emissions between the two methods are smaller, attributed partly to the compensating effects of divergent removal efficiencies of dust collectors applied in the two methods, obtained either from plant-byplant surveys (method A) or from national or provincial average levels (method B). The differences are believed to reflect disparities in the considerable fractions of total emissions from OIN (i.e., industrial sources excluding iron and steel, cement, and chemical plants, for which information is relatively clear, as defined in Sect. 2.1), specifically 6, 22, 15 , and $24 \%$ of $\mathrm{SO}_{2}, \mathrm{NO}_{x}, \mathrm{PM}_{2.5}$, and $\mathrm{CO}$ for lime production, as shown in Table 3. The results suggest relatively large uncertainties in city-level emission estimates lacking sufficient individual source information. In this case, moreover, the overestimates in Nanjing's emissions from downscaling provincial emissions would inevitably lead to underestimates for other cities within the province, weakening understanding of emission sources and the quantitative basis of regional control policies.

\section{Policy implications}

\subsection{The effects of pollution control policies on emission abatement and air quality}

Substantial efforts have been undertaken in specific Chinese sectors to achieve national targets in both energy conservation and emission reduction (Zhao et al., 2013). Under the air pollution control measures, clear benefits in emission abatement, particularly in the power and transportation sectors, are found for Nanjing from 2010 to 2012, a relatively short period. In the power sector, electricity generation increased by $58 \%$ during 2010-2012 while that specifically from coalfired plants grew by $47 \%$, reflecting the switch of coal to gas combustion and other diversification of power generation in the city. Meanwhile, coal consumption of the power sector increased by only $25 \%$, much slower than the resulting electricity generation, reflecting improved energy efficiency due to replacement of small and old power units with larger and more energy-efficient ones. As shown in Fig. S10a in the Supplement, the capacity share of large units (above $300 \mathrm{MW}$ (megawatts)) increased from $72 \%$ in 2010 to $78 \%$ in 2012 , while that of small ones (below $100 \mathrm{MW}$ ) decreased from 20 to $16 \%$. The penetration of large units raised as well the use of APCD for $\mathrm{SO}_{2}, \mathrm{NO}_{x}$, and PM, leading to significant reduction of emission factors by 30,23 , and $22 \%$, respectively. The decrease in emission factors can also be seen for vehicles. With the implementation of staged emission standards for new vehicles from 2010 to 2012, the emission factors of $\mathrm{SO}_{2}, \mathrm{NO}_{x}, \mathrm{CO}$, and VOCs are estimated to have declined by $66,33,34$, and $37 \%$ for gasoline vehicles (Fig. S10b); those of $\mathrm{NO}_{x}, \mathrm{CO}$, and VOCs by 12,13 , and $24 \%$ for diesel vehicles (Fig. S10c); and those of CO and VOCs by 25 and $34 \%$ for motorcycles (Fig. S10d), respectively. The $\mathrm{SO}_{2}, \mathrm{CO}$, and VOC emissions from on-road transportation decreased by 39 , 11 , and $27 \%$, respectively, while the vehicle population increased by $27 \%$ in the city over the 3 years.

The benefits of emission control on air quality can be partly confirmed by comparisons of changes in emissions and ambient concentrations. During 16-24 August 2013 when the 2nd Asian Youth Games (AYG) were held in Nanjing, a series of extra emission controls measures were undertaken by the government to improve air quality for the Games. 
Those measures included increasing use of low-sulfur coal at power plants, closing small factories with relatively large pollutant emissions, stopping construction in some regions, and restricting traffic. Taking these extra measures into account, the emissions of $\mathrm{SO}_{2}, \mathrm{NO}_{x}, \mathrm{PM}_{2.5}, \mathrm{PM}_{10}$, and $\mathrm{CO}$ over 16-24 August 2013 are estimated to have declined 23, $31,21,14$, and $33 \%$, respectively, compared to those in the same period in 2012, based on the monthly distributions described in Sect. 3.2 (see Table S5 in the Supplement). Correspondingly, the daily average concentrations for those pollutants in Nanjing during the AYG period were found to decline by $22,27,10,5$, and $22 \%$, respectively, compared to the same period in 2012 (Yu et al., 2014). Although changes in other factors including meteorological conditions also influenced air quality, the consistency between the reduced emissions and concentrations suggests that local emission abatement played a primary role in the air quality improvement.

\subsection{Effects of super emitters and small sources on emission levels and spatial distributions}

For cities with intensive, heavily polluting industries like Nanjing, large point sources with significant energy consumption and/or industrial production are estimated to dominate the levels and spatial distribution of emissions of the city. As shown in Fig. 3, the areas with high emission densities in Nanjing are in good agreement with geographical locations of point sources for all pollutants. The 10 largest point sources of $\mathrm{SO}_{2}$ emissions are estimated to account for $54 \%$ of total emissions in the city (Fig. 2a), and the analogous number for $\mathrm{NO}_{x}$ is $43 \%$ (Fig. 2b). For $\mathrm{PM}_{2.5}$, as shown in Fig. 2c, the 10 largest sources are estimated to be responsible for $75 \%$ of total primary emissions in Nanjing (excluding construction and road dust). In particular, extremely high emissions are found for iron and steel plants, resulting mainly from the high production of steel and reliance on wet scrubbers with relatively low removal efficiencies (annual average of $85 \%$ ) in the exhaust streams of basic oxygen furnaces. Similarly, the 10 largest refineries and chemical plants shown in Fig. 2d are responsible for $52 \%$ of VOC emissions in Nanjing. The dominant roles of these big sources on emission levels and spatial distributions indicate that careful investigation and analysis of source-specific parameters relevant to emissions from these super emitters (e.g., removal efficiency of APCDs) are particularly crucial to the reliability of cityscale emission inventories.

Although large point sources dominate emissions at the city level, the contributions from scattered small sources cannot be overlooked. As shown in Fig. 3, the fractions of air pollutant emissions from power, cement, iron and steel, and chemical plants to the city's total emissions are estimated to range from 38 to $88 \%$, significantly lower than that of coal consumption (96\%). Despite the tiny share of coal use, decentralized small coal combustion sources have a relatively high proportion of emissions, resulting from poorer emis- sion control technologies and management than big enterprises. Regarding emission abatement and air quality improvement, it is imperative to expand pollution control from large sources to small- and medium-sized enterprises, as the potential for further reductions from the major sources is diminishing due to near-saturation of APCDs. As for improvement of emission inventories, more varied and uncertain emission factors for small boilers and kilns result from much greater diversities of manufacturing technologies. This necessitates more field measurements in the future to inform the application of emission factors in inventories and to better understand the emission characteristics of small sources.

\section{Conclusions}

With updated methods and substantial new data on local emission sources, a city-scale emission inventory of air pollutants and $\mathrm{CO}_{2}$ has been developed for Nanjing for 3 years, 2010-2012. Through plant-by-plant on-site surveys, emission factors, spatial and temporal emission distributions, and estimates of total emissions for major sources (power, cement, iron and steel, and refineries and chemical plants) are especially improved. Emissions in the city are dominated by large point sources, or super emitters. Despite large increases in energy consumption and industrial production, the emissions of most concerned pollutants were largely stable during the period, particularly $\mathrm{SO}_{2}$ and $\mathrm{NO}_{x}$, attributed to increased use and air pollutant removal rates of APCDs under national policies of air pollution control. The current estimates are consistent with the interannual variability of $\mathrm{NO}_{2}$ VCD observed from OMI. The improvement of emission estimates by city-scale assessment is further indicated by analyses of spatial correlations with observations by satellite (for $\mathrm{NO}_{x}$ ) and ground stations (for $\mathrm{SO}_{2}, \mathrm{NO}_{x}$, and $\mathrm{CO}$ ), as well as by top-down constraints $\left(\mathrm{BC} / \mathrm{CO}, \mathrm{OC} / \mathrm{EC}\right.$, and $\left.\mathrm{CO}_{2} / \mathrm{CO}\right)$ provided by ground-based observations. Analyses of bottomup emission inventories, moreover, can identify possible errors in observational data sets, encouraging further investigation.

Limitations remain in the current work. First, some available and potentially valuable information cannot yet be fully exploited to improve emission estimates. CEMS data help to determine the time distribution of emissions, for example, but are currently less useful for estimating absolute emission levels, due to incompleteness and systematic errors in relevant parameters (e.g., flue gas flow rate). Second, since emission factors for some sources are still based on provincial or national assessments due to lack of local information, the uncertainties of the city-scale emission inventory have not yet been systematically quantified. In particular, the degree of uncertainty in the city-scale inventory compared to that of national ones remains unknown. Finally, it is currently difficult to assess emissions of some species believed to have high emission uncertainty, e.g., VOC and $\mathrm{NH}_{3}$, due to lack 
of sufficient instrumental observations. More field measurements of both emissions and ambient levels of these species are thus recommended in the future.

\section{The Supplement related to this article is available online at doi:10.5194/acp-15-12623-2015-supplement.}

Acknowledgements. This work was sponsored by the Natural Science Foundation of China (41575142 and 41205110), Natural Science Foundation of Jiangsu (BK20140020 and BK2012310), Jiangsu Science and Technology Support Program (SBE2014070918), Ministry of Science and Technology of China (2011BAK21B00), and Ministry of Education of China (20120091120019). We would like to thank Hongxin Bao and Danning Zhang from NJEPB for technical support of this work, Jintai Lin from Peking University for comments on satellite observation, and TEMIS for free use of their monitoring data. Thanks also go to two anonymous reviewers for their very valuable comments to improve this work. The contents of this paper are solely the responsibility of the authors and do not necessarily represent the official views of the sponsors.

Edited by: G. Frost

\section{References}

Akimoto, H., Oharaa, T., Kurokawac, J. I., and Horii, N.: Verification of energy consumption in China during 1996-2003 by using satellite observational data, Atmos. Environ., 40, 7663-7667, 2006.

Boersma, K. F., Eskes, H. J., Veefkind, J. P., Brinksma, E. J., van der A, R. J., Sneep, M., van den Oord, G. H. J., Levelt, P. F., Stammes, P., Gleason, J. F., and Bucsela, E. J.: Near-real time retrieval of tropospheric $\mathrm{NO}_{2}$ from OMI, Atmos. Chem. Phys., 7, 2103-2118, doi:10.5194/acp-7-2103-2007, 2007.

Boersma, K. F., Eskes, H. J., Dirksen, R. J., van der A, R. J., Veefkind, J. P., Stammes, P., Huijnen, V., Kleipool, Q. L., Sneep, M., Claas, J., Leitão, J., Richter, A., Zhou, Y., and Brunner, D.: An improved tropospheric $\mathrm{NO}_{2}$ column retrieval algorithm for the Ozone Monitoring Instrument, Atmos. Meas. Tech., 4, 19051928, doi:10.5194/amt-4-1905-2011, 2011.

Cai, H. and Xie, S. D.: Determination of emission factors from motor vehicles under different emission standards in China, Acta Scientiarum Naturalium Universitatis Pekinensis, 3, 319-326, 2010 (in Chinese).

Castro, L. M., Pio, C. A., Harrison, R. M., and Smith, D. J. T.: Carbonaceous aerosol in urban and rural European atmospheres: estimation of secondary organic carbon concentrations, Atmos. Environ., 33, 2771-2781, 1999.

Cheng, Y., He, K. B., Duan, F. K., Zheng, M., Ma, Y. L., and Tan, J. H.: Measurement of semivolatile carbonaceous aerosols and its implications: A review, Environ. Int., 35, 674-681, 2009.

Chow, J. C., Watson, J. G., Chen, L.-W. A., Rice, J., and Frank, N. H.: Quantification of $\mathrm{PM}_{2.5}$ organic carbon sampling arti- facts in US networks, Atmos. Chem. Phys., 10, 5223-5239, doi:10.5194/acp-10-5223-2010, 2010.

Cui, H., Mao, P., Zhao, Y., Nielsen, C. P., and Zhang, J.: Patterns in atmospheric carbonaceous aerosols in China: emission estimates and observed concentrations, Atmos. Chem. Phys., 15, 86578678, doi:10.5194/acp-15-8657-2015, 2015.

Dong, W. X., Xing, J., and Wang, S. X.: Temporal and spatial distribution of anthropogenic ammonia emissions in China, Environ. Sci., 31, 1457-1463, 2010 (in Chinese).

Duncan, B. N., Logan, J. A., Bey, I., Megretskaia, I. A., Yantosca, R. M., Novelli, P. C., Jones, N. B., and Rinsland, C. P. Global budget of CO, 1988-1997: Source estimates and validation with a global model, J. Geophys. Res., 112, D22301, doi:10.1029/2007JD008459, 2007.

EEA (European Environment Agency): COPERT 4-Computer Programme to Calculate Emissions from Road Transport, User Manual (Version 9.0), Copenhagen, Denmark, 2012.

EEA (European Environment Agency): EMEP/CORINAIR Emission Inventory Guidebook-2013, available at: http://www.eea. europa.eu/publications/emep-eea-guidebook-2013 (last access: 10 November 2015), 2013.

Fan, S. B., Tian, G., Li, G., and Shao, X.: Emission characteristics of paved roads fugitive dust in Beijing, Environ. Sci., 28, 23962399, 2007 (in Chinese).

Fu, X., Wang, S., Zhao, B., Xing, J., Cheng, Z., Liu, H., and Hao, J.: Emission inventory of primary pollutants and chemical speciation in 2010 for the Yangtze River Delta region, China, Atmos. Environ., 70, 39-50, 2013.

Guan, D., Liu, Z., Geng, Y., Lindner, S., and Hubacek, K.: The gigatonne gap in China's carbon, Nat. Clim. Change, 2, 672-675, 2012.

Hirsch, R. M. and Gilroy, E. J.: Methods of fitting a straight-line to data-Examples in water resources, Water Resour. Bull., 20, 705711, 1984.

Hu, M., Deng, Z., Wang, Y., Lin, P., Zeng, L., Kondo, Y., and Zhao, Y.: Comparison of EC / OC in $\mathrm{PM}_{2.5}$ between filter sampling offline analysis and in situ on-line measurement, Environ. Sci., 29, 3297-3303, 2008 (in Chinese).

Huang, C., Chen, C. H., Li, L., Cheng, Z., Wang, H. L., Huang, H. Y., Streets, D. G., Wang, Y. J., Zhang, G. F., and Chen, Y. R.: Emission inventory of anthropogenic air pollutants and VOC species in the Yangtze River Delta region, China, Atmos. Chem. Phys., 11, 4105-4120, doi:10.5194/acp-11-4105-2011, 2011.

Huang, K., Fu, J. S., Gao, Y., Dong, X. Y., Zhuang, G. S., and Lin, Y. F.: Role of sectoral and multi-pollutant emission control strategies in improving atmospheric visibility in the Yangtze River Delta, China, Environ. Pollut., 184, 426-434, 2014.

Huang, R. J., Zhang, Y., Bozzetti, C., Ho, K. F., Cao, J. J., Han, Y., Daellenbach, K. R., Slowik, J. G., Platt, S. M., Canonaco, F., Zotter, P., Wolf, R., Pieber, S. M., Bruns, E. A., Crippa, M., Ciarelli, G., Piazzalunga, A., Schwikowski, M., Abbaszade, G., SchnelleKreis, J., Zimmermann, R., An, Z., Szidat, S., Baltensperger, U., Haddad, I. E., and Prevot, A. S.: High secondary aerosol contribution to particulate pollution during haze events in China, Nature, 514, 218-222, 2014.

Huang, X., Huang, X. X., Wang, T. J., Zhuang, B. L., Li, S., Xie, M., Han, Y., Yang, X. Q., Sun, J. N., Ding, A. J., and Fu, Z. B.: Observation and analysis of urban upper atmospheric carbon monoxide in Nanjing, China Environ. Sci., 33, 1577-1584, 2013. 
Huang, Y. M.: Study on the emission estimation and spatial distribution of urban fugitive dust, Master thesis, East China Normal University, Shanghai, 2006 (in Chinese).

Kim, S.-W., Heckel, A., Frost, G. J., Richter, A., Gleason, J., Burrows, J. P., McKeen, S., Hsie, E.-Y., Granier, C., and Trainer, M.: $\mathrm{NO}_{2}$ columns in the western United States observed from space and simulated by a regional chemistry model and their implications for $\mathrm{NO}_{x}$ emissions, J. Geophys. Res., 114, D11301, doi:10.1029/2008JD011343, 2009.

Kondo, Y., Oshima, N., Kajino, M., Mikami, R., Motcki, N., Takegawa, N., Verma, R. L., Kajii, Y., Kato, S., and Takami, A.: Emissions of black carbon in East Asia estimated from observations at a remote site in the East China Sea, J. Geophys. Res., 116, D16201, doi:10.1029/2011JD015637, 2011.

Kurokawa, J., Ohara, T., Morikawa, T., Hanayama, S., JanssensMaenhout, G., Fukui, T., Kawashima, K., and Akimoto, H.: Emissions of air pollutants and greenhouse gases over Asian regions during 2000-2008: Regional Emission inventory in ASia (REAS) version 2, Atmos. Chem. Phys., 13, 11019-11058, doi:10.5194/acp-13-11019-2013, 2013.

Lei, Y., Zhang, Q., Nielsen, C. P., and He, K. B.: An inventory of primary air pollutants and $\mathrm{CO}_{2}$ emissions from cement industry in China, 1990-2020, Atmos. Environ., 45, 147-154, 2011.

Li, B., Zhang, J., Zhao, Y., Yuan, S. Y., Zhao, Q. Y., Shen, G. F., and $\mathrm{Wu}, \mathrm{H}$. S.: Seasonal variation of urban carbonaceous aerosols in a typical city Nanjing in Yangtze River Delta, China, Atmos. Environ., 106, 223-231, 2015.

Li, X. H., Wang, S. X., Duan, L., Hao, J. M., Li, C., Chen, Y. S., and Yang, L.: Particulate and trace gas emissions from open burning of wheat straw and corn stover in China, Environ. Sci. Technol., 41, 6052-6058, 2007.

Lin, J.-T.: Satellite constraint for emissions of nitrogen oxides from anthropogenic, lightning and soil sources over East China on a high-resolution grid, Atmos. Chem. Phys., 12, 2881-2898, doi:10.5194/acp-12-2881-2012, 2012.

McDonald, B. C., Goldstein, A. H., and Harley, R. A.: Long-term trends in California mobile source emissions and ambient concentrations of black carbon and organic aerosols, Environ. Sci. Technol., 49, 5178-5188, 2015.

Mijling, B., van der A, R. J., and Zhang, Q.: Regional nitrogen oxides emission trends in East Asia observed from space, Atmos. Chem. Phys., 13, 12003-12012, doi:10.5194/acp-1312003-2013, 2013.

NBSC (National Bureau of Statistics of China): China Statistical Yearbook, Beijing, China Statistics Press, 2013 (in Chinese).

NJCLCC (Nanjing Committee of Local Chronicles Compilation): Nanjing Almanac, Nanjing, Editorial Department of Nanjing Almanac, 2011.

NJNBS (Nanjing Bureau of Statistics): Statistical Yearbook of Nanjing, Beijing, China Statistics Press, 2013 (in Chinese).

Ohara, T., Akimoto, H., Kurokawa, J., Horii, N., Yamaji, K., Yan, X., and Hayasaka, T.: An Asian emission inventory of anthropogenic emission sources for the period 1980-2020, Atmos. Chem. Phys., 7, 4419-4444, doi:10.5194/acp-7-4419-2007, 2007.

Seiler, W., Giehl, H., Brunke, E. G., and Halliday, E.: The seasonality of CO abundance in the Southern Hemisphere, Tellus B, 36, 219-231, 1984.
Sinton, J. E.: Accuracy and reliability of China's energy statistics, China Econ. Rev., 12, 373-383, 2001.

Streets, D. G., Bond, T. C., Carmichael, G. R., Fernandes, S. D., Fu, Q., He, D., Klimont, Z., Nelson, S. M., Tsai, N. Y., Wang, M. Q., Woo, J.-H., and Yarber, K. F.: An inventory of gaseous and primary aerosol emissions in Asia in the year 2000, J. Geophys. Res., 108, 8809, doi:10.1029/2002JD003093, 2003.

Timmermans, R. M. A., Denier van der Gon, H. A. C., Kuenen, J. J. P., Segers, A. J., Honoré, C., Perrussel, O., Builtjes, P. J. H., and Schaap, M.: Quantification of the urban air pollution increment and its dependency on the use of down-scaled and bottom-up city emission inventories, Urban Climate, 6, 44-62, 2013.

Tohjima, Y., Kubo, M., Minejima, C., Mukai, H., Tanimoto, H., Ganshin, A., Maksyutov, S., Katsumata, K., Machida, T., and Kita, K.: Temporal changes in the emissions of $\mathrm{CH}_{4}$ and $\mathrm{CO}$ from China estimated from $\mathrm{CH}_{4} / \mathrm{CO}_{2}$ and $\mathrm{CO} / \mathrm{CO}_{2}$ correlations observed at Hateruma Island, Atmos. Chem. Phys., 14, 1663-1677, doi:10.5194/acp-14-1663-2014, 2014.

US EPA (US Environmental Protection Agency): Compilation of Air Pollutant Emission Factors (AP-42), fifth edition, available at: http://www.epa.gov/ttnchie1/ap42/ (last access: 10 November 2015), 2002.

Wang, L. T., Wei, Z., Yang, J., Zhang, Y., Zhang, F. F., Su, J., Meng, C. C., and Zhang, Q.: The 2013 severe haze over southern Hebei, China: model evaluation, source apportionment, and policy implications, Atmos. Chem. Phys., 14, 3151-3173, doi:10.5194/acp-14-3151-2014, 2014.

Wang, L., Zhang, P., Tan, S., Zhao, X., Cheng, D., Wei, W., Su, J., and Pan, X.: Assessment of urban air quality in China using air pollution indices (APIs), J. Air Waste Ma., 63, 170-178, 2013.

Wang, S., Zhao, M., Xing, J., Wu, Y., Zhou, Y., Lei, Y., He, K., Fu, L., and Hao, J.: Quantifying the air pollutants emission reduction during the 2008 Olympic Games in Beijing, Environ. Sci. Technol., 44, 2490-2496, 2010.

Wang, Y., Munger, J. W., Xu, S., McElroy, M. B., Hao, J., Nielsen, C. P., and Ma, H.: $\mathrm{CO}_{2}$ and its correlation with $\mathrm{CO}$ at a rural site near Beijing: implications for combustion efficiency in China, Atmos. Chem. Phys., 10, 8881-8897, doi:10.5194/acp-10-88812010, 2010.

Wang, Y. X., Wang, X., Kondo, Y., Kajino, M., Munger, J. W., and Hao, J. M.: Black carbon and its correlation with trace gases at a rural site in Beijing: Top-down constraints from ambient measurements on bottom-up emissions, J. Geophys. Res., 116, D24304, doi:10.1029/2011JD016575, 2011.

Wei, W., Wang, S. X., Chatani, S., Klimont, Z., Cofala, J., and Hao, J. M.: Emission and speciation of non-methane volatile organic compounds from anthropogenic sources in China, Atmos. Environ., 42, 4976-4988, 2008.

Xiao, J. H., Ma, W., Wang, J. X., and Wang, X. W.: A simulation of cold start emission characteristics of gasoline engine with EuroIII cycle on engine test bench, Automot. Eng., 6, 639-647, 2004 (in Chinese).

Yang, Z. P.: Estimation of ammonia emission from livestock in China based on mass-flow method and regional comparison, Master thesis, Peking University, Beijing, 2008 (in Chinese).

Ye, S. Q., Zheng, J. Y., Pan, Y. Y., Wang, S. S., Lu, Q., and Zhong, L. J.: Marine emission inventory and its temporal and spatial characteristics in Guangdong Province, Acta Sci. Circum., 34, 537547, 2014 (in Chinese). 
Yin, S. S., Zheng, J. Y., Zhang, L. J., and Zhong, L. J.: Anthropogenic ammonia emission inventory and characteristic in the Pearl River Delta region, Environ. Sci., 31, 1146-1151, 2010 (in Chinese).

Yu, Y. Y., Xie, F. J., Lu, X. B., Zhu, Z. F., and Shu, Y.: The environmental air quality condition and the reason analysis during the Asian Youth Games of Nanjing, Environmental Monitoring and Forewarning, 6, 5-17, 2014 (in Chinese).

Zhang, L. J., Zheng, J. Y., Yin, S. S., Peng, K., and Zhong, L. J.: Development of non-road mobile source emission inventory for the Pearl River Delta region, Environ. Sci., 31, 886-891, 2010 (in Chinese).

Zhang, Q., Streets, D. G., Carmichael, G. R., He, K. B., Huo, H., Kannari, A., Klimont, Z., Park, I. S., Reddy, S., Fu, J. S., Chen, D., Duan, L., Lei, Y., Wang, L. T., and Yao, Z. L.: Asian emissions in 2006 for the NASA INTEX-B mission, Atmos. Chem. Phys., 9, 5131-5153, doi:10.5194/acp-9-5131-2009, 2009.

Zhang, Q., Geng, G. N., Wang, S. W., Richter, A., and He, K. B.: Satellite remote sensing of changes in $\mathrm{NO}_{x}$ emissions over China during 1996-2010, Chinese. Sci. Bull., 57, 2857-2864, 2012 a.

Zhang, Q., He, K., and Huo, H.: Cleaning China's air, Nature, 484, 161-162, 2012b.

Zhao, P. S., Feng, Y. C., Jin, J., Han, B., Bi, X. H., Zhu, T., and Zhang, X. L.: Characteristics and control indicators of fugitive dust from building construction sites, Acta Sci. Circum., 29, 1618-1623, 2009 (in Chinese).

Zhao, Y., Wang, S. X., Duan, L., Lei, Y., Cao, P. F., and Hao, J. M.: Primary air pollutant emissions of coal-fired power plants in China: current status and future prediction, Atmos. Environ., 42, 8442-8452, 2008.

Zhao, Y., Wang, S. X., Nielsen, C. P., Li, X. H., and Hao, J. M.: Establishment of a database of emission factors for atmospheric pollutants from Chinese coal-fired power plants, Atmos. Environ., 44, 1515-1523, 2010.
Zhao, Y., Nielsen, C. P., Lei, Y., McElroy, M. B., and Hao, J.: Quantifying the uncertainties of a bottom-up emission inventory of anthropogenic atmospheric pollutants in China, Atmos. Chem. Phys., 11, 2295-2308, doi:10.5194/acp-11-2295-2011, 2011.

Zhao, Y., Nielsen, C. P., McElroy, M. B., Zhang, L., and Zhang, J.: CO emissions in China: uncertainties and implications of improved energy efficiency and emission control, Atmos. Environ., 49, 103-113, 2012a.

Zhao, Y., Nielsen, C. P., and McElroy, M. B.: China's $\mathrm{CO}_{2}$ emissions estimated from the bottom up: Recent trends, spatial distributions, and quantification of uncertainties, Atmos. Environ., 59, 214-223, 2012b.

Zhao, Y., Zhang, J., and Nielsen, C. P.: The effects of recent control policies on trends in emissions of anthropogenic atmospheric pollutants and $\mathrm{CO}_{2}$ in China, Atmos. Chem. Phys., 13, 487-508, doi:10.5194/acp-13-487-2013, 2013.

Zhao, Y., Zhang, J., and Nielsen, C. P.: The effects of energy paths and emission controls and standards on future trends in China's emissions of primary air pollutants, Atmos. Chem. Phys., 14, 8849-8868, doi:10.5194/acp-14-8849-2014, 2014.

Zheng, B., Huo, H., Zhang, Q., Yao, Z. L., Wang, X. T., Yang, X. F., Liu, H., and He, K. B.: High-resolution mapping of vehicle emissions in China in 2008, Atmos. Chem. Phys., 14, 9787-9805, doi:10.5194/acp-14-9787-2014, 2014.

Zheng, J., Zhang, L., Che, W., Zheng, Z., and Yin, S.: A highly resolved temporal and spatial air pollutant emission inventory for the Pearl River Delta region, China and its uncertainty assessment, Atmos. Environ., 43, 5112-5122, 2009.

Zhou, W., Wang, X., Zhang, Y., Su, H., and Lu, K.: Current status of nitrogen oxides related pollution in China and integrated control strategy, Acta Scientiarum Naturalium Universitatis Pekinensis, 44, 323-330, 2008 (in Chinese). 